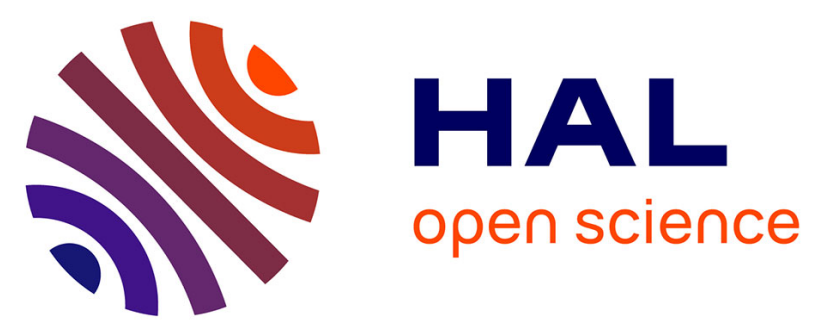

\title{
Columnar structures in pyrometamorphic rocks associated with coal-bearing spoil-heaps burned by self-ignition, La Ricamarie, Loire, France
}

Bernard Guy, Vincent Thiery, Daniel Garcia, Jerôme Bascou, Maarten

A.T.M. Broekmans

\section{To cite this version:}

Bernard Guy, Vincent Thiery, Daniel Garcia, Jerôme Bascou, Maarten A.T.M. Broekmans. Columnar structures in pyrometamorphic rocks associated with coal-bearing spoil-heaps burned by self-ignition, La Ricamarie, Loire, France. Mineralogy and Petrology, In press, 114, pp.465 à 487. 10.1007/s00710020-00719-7 . emse-02965454

\section{HAL Id: emse-02965454 \\ https://hal-emse.ccsd.cnrs.fr/emse-02965454}

Submitted on 19 Oct 2020

HAL is a multi-disciplinary open access archive for the deposit and dissemination of scientific research documents, whether they are published or not. The documents may come from teaching and research institutions in France or abroad, or from public or private research centers.
L'archive ouverte pluridisciplinaire HAL, est destinée au dépôt et à la diffusion de documents scientifiques de niveau recherche, publiés ou non, émanant des établissements d'enseignement et de recherche français ou étrangers, des laboratoires publics ou privés. 


\title{
Columnar structures in pyrometamorphic rocks associated with coal- bearing spoil-heaps burned by self-ignition, La Ricamarie, Loire, France
}

Bernard Guy ${ }^{\mathrm{a}, *}$, Vincent Thiéry $^{\mathrm{b}}$, Daniel Garcia ${ }^{\mathrm{a}}$, Jérôme Bascou ${ }^{\mathrm{c}}$, Maarten A.T.M. Broekmans ${ }^{\mathrm{d}}$

a: $\quad$ Ecole des Mines de Saint-Étienne, Institut Mines Télécom, UMR CNRS EVS

(Environnement, Ville, Société), Université de Lyon. 158 Cours Fauriel, F-42023 SaintEtienne, France

b: IMT Lille-Douai and Université de Lille, LGCgE, CERI « Matériaux et Procédés », 764 Boulevard Lahure, F-59500 Douai, France

c: Université de Lyon, UJM Saint-Etienne, UMR CNRS IRD 6524 Laboratoire Magmas et volcans, F-42023 Saint-Etienne, France

d: Department of Laboratory, Geological Survey of Norway - NGU, PO Box 6315 Torgarden, Trondheim, Norway

\begin{abstract}
This paper reports the discovery of columnar structures within paralavas from an active burning coal heap located in the formerly exploited coal basin of Saint-Étienne, Loire, France. The word "paralava" in this work refers to a rock that looks similar on the field to some volcanic rocks (e.g. basalts), and has been partially molten (with up to 50-60 vol\% liquid). Here, the comparison between paralavas and volcanic rocks is mainly made from the point of view of the solidification process. The columnar structures occur in a decametric "sill", located in the inner parts of the heap, exposed by quarrying operations. They are irregular;
\end{abstract}

\footnotetext{
* Corresponding author: E: guy@emse.fr, T: + 33620072314
} 
they form prisms of ca. 50 centimeters in diameter and are up to 2 to 4 meters high. We report on geological, mineralogical, petrographical, geochemical, petrophysical (anisotropy of magnetic susceptibility, AMS) studies, focusing on the columns. Heterogeneities with cylindrical symmetry from the center to the rim of the columns are observed at the decimeter scale, both for geochemistry (variation of $\mathrm{Zn}$ is conspicuous) and AMS studies. These contribute to the understanding of the genesis of the columns, favoring the fingering hypothesis: formation of digitations within a phenomenon of constitutional supercooling (fingers of the solid grow at the expense of the liquid). Among the volatiles playing a role in this phenomenon, the role of $\mathrm{Cl}$ as a ligand to $\mathrm{Zn}$ in the melt deserves attention (the situation is different in standard basaltic rocks, where the role of $\mathrm{H}_{2} \mathrm{O}$ with respect to other volatiles is more important; $\mathrm{Cl}$ may be abundant as a companion to coal).

Keywords: France; burning coal heap; paralava; column structures; fingering

\section{Introduction}

Burning coal heaps are typical features from coal-mining areas, e.g. the Silesian coal basin of Poland (Fabiańska et al. 2013; Kruszewski 2013; Ciesielczuk 2015), the North coal basin in France (Masalehdani et al. 2009), Czech Republic (Žáček et al. 2015) or the Chelyabinsk coal basin in Russia (Sokol 2005), amongst others. Regardless which internal or external factor or factors initially contributed to its ignition (e.g. Nichol and Tovey 1998; Misz-Kennan and Fabiańska 2011), an active burning heap is a hazardous site which must be monitored (Carpentier et al. 2005; Nyssen and Vermeersch 2010), especially as catastrophic landslides and explosions have occurred in some of these in the past (Masalehdani and Paquette 2013; Zio and Aven 2013). Complex petrographical and mineralogical transformations occur inside a burning heap ("anthropogenic combustion metamorphism, or anthropogenic pyrometamorphism", Grapes 2011), due to the inherent extreme heterogeneity of the material 
(shales, sandstones, lump coal, coal dust, demolition waste, steel equipment and parts from mining activities, etc.), essentially under ambient pressure.

The temperatures reached inside a burning heap may reach that of a burning coal seam and may anneal rocks without melting, forming so-called 'clinkers' resembling fire bricks (Quintero et al. 2009, Grapes et al. 2011). Instead, rocks of favorable composition may partly melt, occasionally in appearance closely resembling ropey lavas of natural origin ('pahoehoe'), called 'paralavas' after Fermor (1914), as recommended by the International Union of Geological Sciences (IUGS) (Fettes and Desmons 2011; see also Grapes 2011). The 'partial melt' seems to be a characteristic if not diagnostic paralava quality, though subject to local variation due to inherent material heterogeneity.

Let us clarify the vocabulary used in the present paper about the clinker / paralava duality. These two words have a partial overlap, because on the one hand, clinkers may have partially melted (cf. glassy clinker, Grapes et al. 2009) and, on the other hand, paralavas are frequently incompletely melted and can retain a solid charge. These different types of rocks are found in La Ricamarie. Based on their appearance in the field, the following names are applied following the suggestions of Grapes et al. (2009). (i) Clinker, on the first hand, is in the form of versicolor inhomogeneous breccia on the centimeter to decimeter scale. Clinker appears as massive, dense, sintered blocks of variable shape and color, unlike a volcanic rock. (ii) Paralavas, on the other hand, appear as homogeneous masses on a metric to decametric scale, black to dark grey, aphanitic, locally strongly vesicular, with flow textures as common in volcanic rocks (appearance of ropy basaltic lava).

Under the microscope, so-called paralavas show abundant glass, at variance with what is observed in clinkers. A less direct argument is an indication of a flow (Grapes et al. 2009): clinkers show no evidence of flow, whereas the rocks we call paralavas on the field show clear evidence of a flow, as from their study by anisotropy of magnetic susceptibility (AMS), although not necessarily expected (see below). 
In addition, there are so-called buchites, for instance sandstone coal measure intercalations that have been annealed and partially melted. The complex evolution of the rocks in a burning heap can go to segregation processes similar to magmatic differentiation at a local scale, leading to the development of cordierite cumulates (Gawęda et al. 2011) and "parabasalts" (Sharygin et al. 1999). Alternatively, the abundance of cordierite may also result from the heterogeneity of the sedimentary parent rocks (Grapes et al. 2011).

A review of the mineral matter associated to coal can be found in Ward (2016). The mineralogy of the products of combustion or heating has been extensively studied in the case of coal, either in the case of fuel management (Matjie et al. 2012; Creelman et al. 2013; Liu et al. 2013; Chakravarty et al. 2015), either in the case of coal dumps (Ribeiro et al. 2016), but also in the case of brick making (Karaman et al. 2006; Johari et al. 2010). A whole set of chemical elements can accompany coal: sulfur and iron (in pyrite, whose oxidation can accelerate the combustion process), chlorine and nitrogen compounds (the coal contains nitrogen as a component of complex organic compounds; ammonium chloride is one of the product of coal combustion and later precipitation from "fumarolic" gas jets; chlorine commonly is a constituent of mineral chlorides, the so-called saline coals). These various elements will be found in efflorescence of native sulfur, salammoniac, as well as diverse sulfates and chlorides (refer to Lapham et al., 1980).

In the present paper, we discuss the case of a burning coal heap in the Loire region (France), similar to others in the world; we report on some features that do not seem to have been described in the literature to date for similar occurrences, such as the existence of columns similar to those found in basaltic flows. The comparison with volcanic rocks will be made mainly from the point of view of the solidification process, whereas, from the genetic and physico-chemical point of view, the similarities are more limited. The first purpose is to present some original features related to the columnar structure and give some preliminary lines of interpretation (in particular discussing the proposals by Guy, 2010). 


\section{Description of the site and columns outcrop}

\section{General features and history}

The Saint-Pierre heap from la Ricamarie ('Terril Saint-Pierre') is located in the Saint-Étienne coal basin (type locality of the European Stephanian geological age, corresponding to Gzhelian age in international nomenclature) in the center of France (Fig. 1a). Begun in the 1940's, the building of this heap lasted until 1983 and it covers an area of ca. $1.58 \mathrm{~km}^{2}$. It has been emplaced on the location of a former sandstone quarry on the gentle slope of a hillside (Fig. 1b). An aerial photo survey (aerial pictures from the French Geographical Institute) on the period of availability (1942-2005, available online at www.geoportail.fr and reproduced in Thiéry et al. 2018) allows for the monitoring of the successive stages of emplacement of the heap. In the early times (1942-60's), a number of heaps coexisted, that joined into a single heap from ca. 1965. The heap reached its maximum dimensions in the early 1980's when it covered an elliptic area of ca. $600 \mathrm{~m}$. long and $250 \mathrm{~m}$. wide, about $40 \mathrm{~m}$. at the summit.

According to the quarry owner (M. Perrier pers. comm.), the heap comprises wastes from coal mining (ie. sandstone, shale), fly ash waste from a nearby coal power plant no longer in operation, as well as concrete demolition waste (blocks, railway sleepers). This variable content does not seem different from other localities (eg. Skarżyńska 1995).

The amount of coal in the tailings was considerable, especially in the earliest tailings that were manually sorted without washing. In not-yet combusted parts of the heap, sandstone and shale tailings are seen to contain coal seams up to several centimeters thick. Presumably, the heap has been ignited at an early age already, but a date and/or point of ignition cannot be stated with certainty. Today, the heap is still burning, with many active fumaroles (Fig. 2c), and glowing rocks $\left(500-600^{\circ} \mathrm{C}\right)$ visible through cracks a few decimeters deep under the surface. Based upon iron exsolutions in magnetite inclusions within a steel chain found in combusted material, Guy et al. (2001) find the maximum temperature to be in excess of 
$1371{ }^{\circ} \mathrm{C}$ (this value corresponds to a boundary in the $\mathrm{Fe}-\mathrm{O}$ - $\mathrm{T}$ phase diagram and not to an estimate from a specific analysis; see Supplementary material). The still burning heap is currently being extracted for aggregate, exposing its internal structure and diversity of materials, burnt (annealed, molten) or unburnt (Fig. 2).

\section{Description of the columns}

The recent quarrying has revealed a paralava 'sill' within other burnt materials (Fig. 2d) in the heap's interior. The exposed part is approximately $20 \mathrm{~m}$ long and 2-4 $\mathrm{m}$ thick from upper to lower contact, but its lateral extension is currently unknown. The sill has a columnar structure as commonly observed in basaltic and other volcanic (e.g. rhyolitic) lava flows (Fig. 2e). However, the 0.3-0.5 m polygonal columns are less regular in shape and often broken near the middle. Very often, column faces around are concave (Figs 2f, 3), and do not mirror the surface of neighboring columns. They are widely spaced, locally with 'scabs' of deposited material (Fig. 3c). Typical features of the columnar sill, as well as its relation to other parts, are indicated in Fig. 5. This sill has provided most of the sample materials for this study.

\section{Materials and methods}

\section{Collection and selection of samples}

Several types of samples were taken from the heap (Fig. 4). Samples of a few centimeters to a few decimeters in size were taken from various parts of the heap, including the columns, notably shales and sandstones not visually affected by pyrometamorphism, pyrometamorphic rocks (clinkers, paralavas s.l.), and mineral efflorescences deposited on the surface of the heap at the outlet of the hot gas chimneys. Bulk sample size was chosen in accordance with mineral grain size, following the recommendations of Esbensen (2020). These samples have been subjected to the various types of preparation and analysis described in the following sections. 
As for the paralava columns, two types of sampling were specifically carried out: three large pieces (PAC1, 2, 3) of fallen columns (not in place) with a nearly complete section; the size is to about $0.5 \mathrm{~m}$; - smaller pieces of columns ( $\mathrm{cm}$ to $\mathrm{dm}$ ), trying to select the exterior of a column (DR1, 2, 3). The sections of quasi-complete columns (PAC samples) were divided using a large saw. On the first slice of PAC3 sample, a thin section was made at the periphery of the column, and electron-probe micro-analyzer (EPMA) profiles was obtained at the scale of ten millimeters with defocused beam. A series of whole rock geochemical analyses (allowing to draw a chemical profile) were made on all three samples: centimeter size cubic pieces were cut along some twenty centimeter sections from the outside to the inside of the column (numbered A, B, C, .., H, I, J). The chemical composition of DR samples has been analyzed but not as spatial profiles.

The second slice of the columns was cut into small cubes of centimeter size for AMS analysis: PAC2 (eighty-nine cubes) and PAC3 (sixty-six cubes). Each cube is carefully oriented with respect to the column. As these come from fallen blocks, orientation with respect to the compass points in the field is not possible. Numbers of tables and figures, where analytic results on the foregoing samples are displayed, are given in the caption of Fig. 4.

\section{Thin section preparation and optical petrography}

Samples typically weighing several kilograms each were collected during fieldwork in 2016. After cutting billets $\sim 27 \times 47 \times 10 \mathrm{~mm}$, standard-sized thin sections were prepared with successive steps of lapping with silicon carbide abrasives to achieve a final thickness of $\sim 30$ $\mu \mathrm{m}$, following routine procedures modified after Humphries (1992). The surfaces of sections for subsequent analysis in a scanning electron microscope (SEM) with energy-dispersive Xray spectrometry (SEM-EDS) or in an EPMA instrument were polished with diamond pastes 6-3-1-0.25 $\mu \mathrm{m}$. Finally, a conductive carbon coating $\sim 10 \mathrm{~nm}$ was sputtered in a Polaron CC7650 to avoid charging under the e-beam. Thin and polished sections were studied in a 
Zeiss AxioImager M2m petrographic optical microscope in transmitted and incident polarized light, to assess mineral content, microstructure, fabric/texture, and to select inclusion-free locations with straight grain boundaries suitable for SEM-EDS or EPMA assessment.

\section{SEM and EPMA assessment}

Carbon-coated polished sections were assessed in a JEOL 6500 field emission - scanning electron microscope (FE-SEM) instrument at the École des Mines de Saint-Étienne, using back-scattered electron (BSE) imaging sensitive to differences in average atomic number (Z). The FE-SEM instrument was operated in high vacuum $\left(<10^{-5}\right.$ Torr $)$ at $15 \mathrm{kV}$ and $10 \mathrm{nA}$ beam current (on Faraday cup). Qualitative chemical composition was determined using a Bruker X-flash EDS analyzer. Nominal beam diameter was set to $1 \mu \mathrm{m}$, acquisition time to $30 \mathrm{~s}$, detector dead time was kept at $\sim 15 \pm 5 \%$. SEM-based cathodoluminescence (SEM-CL) images were acquired using a Gatan CL2 iBSED detector.

For quantitative assessment of mineral compositions, carbon-coated polished sections were analyzed in a CAMECA SX100 EPMA instrument at the CNRS "Magmas et Volcans" laboratory in Clermont-Ferrand. All elements were measured on $\mathrm{K} \alpha$-lines, and the instrument was calibrated against the following calibrant material: orthoclase for $\mathrm{K}$ and $\mathrm{Al}$, albite for $\mathrm{Na}$, diopside for $\mathrm{Si}, \mathrm{Mg}$ and $\mathrm{Ca}, \mathrm{Fe}$ on $\mathrm{Fe}_{2} \mathrm{O}_{3}, \mathrm{Mn}$ and $\mathrm{Ti}$ on $\mathrm{MnTiO}_{3}$ and $\mathrm{Zn}$ on $\mathrm{ZnO}$. Raw data were ZAF-corrected using the PAP algorithm of Pouchou and Pichoir (1991) as implemented in CAMECA proprietary software. The analytical software includes all main rok-forming elements plus Zn. Measured element contents were recalculated to oxides by stoichiometry, where $\mathrm{Fe}_{2} \mathrm{O}_{3}$ represents total iron (oxide). Net lower limits of detection (LLD) in wt\% are stated per element together with the tabulated data; lower limits of quantification (LLQ) are

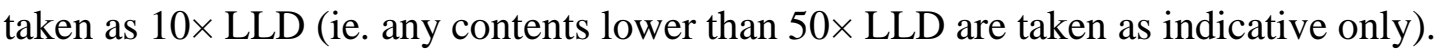

\section{Whole-rock chemical composition}


Whole-rock chemical composition has been obtained by X-ray fluorescence (XRF) and inductively-coupled plasma - optical-emission spectrometry (ICP-OES). Bulk rock samples were cleaned of any weathering and alteration crusts using a diamond blade. Cleaned samples were comminuted in a jaw crusher to pass a sieve $1.0 \mathrm{~mm}$, and split using a Retsch PT100 rotary sample divider to obtain representative $50 \mathrm{~g}$ subsamples for further pulverization in a shatter box with agate lining.

Pre-dried at $105^{\circ} \mathrm{C}, 0.60 \mathrm{~g}$ sample powder was mixed with $4.20 \mathrm{~g}$ of Li-metaborate and digested at $1050^{\circ} \mathrm{C}$ in a Pt-crucible (cf. the Claisse-method), to produce glass beads for whole-rock analysis of main elements by XRF. Weight loss of the final bead was recorded gravimetrically and taken as loss on ignition (LOI). Beads were loaded into the Bruker SRS 3400 spectrometer with a Rh source operated at $40 \mathrm{kV}$ and $40 \mathrm{~mA}$, and analyzed for $\mathrm{Na}, \mathrm{K}$, $\mathrm{Mg}, \mathrm{Ca}, \mathrm{Al}, \mathrm{Fe}, \mathrm{Mn}, \mathrm{Ti}, \mathrm{Si}$, and P. Measured element contents were converted to oxides assuming stoichiometry.

For analysis of trace element contents, separate $0.50 \mathrm{~g}$ aliquots of pre-dried sample powder were digested in $5.00 \mathrm{~mL}$ mix of concentrated strong acids consisting of 5 parts perchloric $\left(\mathrm{HClO}_{4}\right), 3$ parts nitric acid $\mathrm{HNO}_{3}$, and 2 parts hydrofluoric acid (HF). The powder and acid mixture were put in a PTFE jar and gently shaken in a sand bed at $80 \pm 2{ }^{\circ} \mathrm{C}$ until completely digested and dried. The remaining salts were re-dissolved in $5.000 \mathrm{~mL}$ dilute $0.1 \mathrm{~N}$ nitric acid and transferred to a PE vial for measurement and storage. Prepared solutions were measured in a Horiba Jobin-Yvon ICP-OES. XRF and ICP-OES instruments were calibrated against in-house and accredited standards, and blind duplicates were inserted in the sample series. LLD values are indicated per main element oxide (in wt $\%$ ) and/or trace element (in ppm as $\mu \mathrm{g} \cdot \mathrm{g}^{-1}$ ) together with the tabulated data, LLQ values are considered $10 \times$ LLD as mentioned earlier in this paper. 


\section{X-ray powder diffraction (XRD)}

Pre-crushed whole-rock sample material (see preceding subsection) was further comminuted in a percussion mortar to pass a $0.40 \mathrm{~mm}$ sieve. About $4 \mathrm{~g}$ of sample material was milled for $5 \mathrm{~m}$ in a McCrone Micronizer with zirconia elements under $\sim 15 \mathrm{~mL}$ isopropanol. After drying and homogenizing, powders were front-loaded in dimpled glass holders and finished plane. Prepared specimens were assessed in a Siemens D5000 diffractometer operated at $40 \mathrm{kV}$ and $30 \mathrm{~mA}$. Diffractograms were recorded using bulk CuK $\alpha$ radiation $(\lambda=1.541840 \AA)$ from 02 $70^{\circ} 2 \theta$ in $0.02^{\circ} 2 \theta$ increments with $5 \mathrm{~s}$ counting time per step, and total scan time $17000 \mathrm{~s}=4$ h 43 min $20 \mathrm{~s} . \mathrm{CuK} \beta$ was removed by a graphite monochromator in the diffracted beam. Phase identification as well as quantification by Rietveld-analysis was done using BGMN 5.1 freeware (www.bgmn.de). Estimated LLD values are on the order of 1-2 wt $\%$. For identification of efflorescent and/or sublimate mineral phases, carefully collected samples were purified by handpicking under a stereomicroscope, powdered under isopropanol in an agate mortar and pestle, and stray-mounted on a zero-background Si-plate for analysis with the same instrument and conditions, but instead set at $02-70^{\circ} 2 \theta$ in $0.10^{\circ} 2 \theta$ increments with 5 s counting time per step, and total scan time $1700 \mathrm{~s}=28 \mathrm{~min} 20 \mathrm{~s}$.

\section{Anisotropic magnetic susceptibility (AMS) measurements}

To assess anisotropic magnetic susceptibility, $20 \mathrm{~mm}$ thick cross-sections were cut with a water-cooled diamond blade from two sampled near-complete columns, perpendicular to their length. A square cm-grid was drawn on each slab with an indelible marker, and cores of $25 \times 20 \mathrm{~mm}$ were extracted using a water-cooled diamond core drill. After drying at ambient conditions, anisotropy of magnetic susceptibility was measured in 3D rotation at $967 \mathrm{~Hz}$ in an MFK1-FA Kappabridge from AGICO, located at the Laboratoire Magmas et Volcans, University of St Etienne. 


\section{Results}

\section{Mineralogy of efflorescences and sublimates}

Native arsenic (As), sulfur (S), as well as realgar $\left(\mathrm{As}_{4} \mathrm{~S}_{4}\right)$, orpiment $\left(\mathrm{As}_{2} \mathrm{~S}_{3}\right)$, claudetite $\left(\mathrm{As}_{2} \mathrm{O}_{3}\right)$, jarosite $\left(\mathrm{KFe}_{3}\left[\mathrm{SO}_{4}\right]_{2}[\mathrm{OH}]_{6}\right)$, and salammoniac $\left(\mathrm{NH}_{4} \mathrm{Cl}\right)$, have all been identified in efflorescence and sublimate deposits at or near the heap surface in fumaroles above actively burning zones, in particular close to column edges (Supplementary Material, Fig. S1; see also Thiéry et al. 2018). These minerals have been observed in similar settings elsewhere, eg. Chesnokov and Tscherbakova (1991), Masalehdani et al. (2009), Grapes (2011), Witzke et al. (2015), Žáček and Skála (2015).

\section{Mineralogy and petrography of clinker}

The particle size range and variability of raw, burnt, annealed and partially melted rocks (clinker) as well as byproducts present in the heap is substantial. The consolidated material allows quarrying with high benches and steep workfaces. The produced material predominantly consists of burnt waste from coal mine, of which several types are present (Thiéry and Guy 2015). Assessment using an optical petrographic microscope is challenging due to its fine grain size. Therefore, clinker was studied in a SEM using SE, BSE, and CL imaging modes in addition to EDS analysis, and some phases were identified (or confirmed) by XRD.

Clinker is inhomogenous from macroscopic down to microscopic scale of observation (Fig. 6). The color may range from dark grey to brick red, and the mineral content is variable and not always easy to confirm. Matrix glass is present in all sections in submillimeter areas. Dendritic phenocrysts (Fig. 6c) measuring 50-100 $\mu \mathrm{m}$ in a finer-grained matrix have been identified by SEM-EDS as Fe-Mg spinels (Thiéry and Guy 2015), and needle-like crystals (Fig. 6d) as mullite. Mg-rich spinels were not observed; instead, the minerals are rich in the hercynite end-member. Despite a high whole-rock Al-content, corundum was not identified, 
as is normal: it would react with $\mathrm{SiO}_{2}$ phases and high-silica glass and their coexistence would be impossible according to the phase diagram. In fine-grained dark patches (Fig. 6e), colorless euhedral crystals have been identified by XRD as indialite (Fig. 6f).

\section{Mineralogy and petrography of columnar and non-columnar paralavas}

At La Ricamarie, paralavas are generally red or black, highly vesicular rocks, similar in appearance to some natural volcanic rocks. Vesicles are round but commonly of irregular shape (Fig. 6 and 7, and Supplementary Fig. S2). Paralavas have a glassy matrix hosting tiny microcrysts of high-temperature minerals in the micron range, together with millimeter-sized relics or pseudomorphs of detrital precursors. Detrital muscovite and structurally related layered silicates (clay minerals) are very common in the sandstones that derive from Hercynian granites surrounding the Carboniferous basin (Chenevoy 1971). Layered silicates have been melted and transformed to complex mullite + glass \pm spinel intergrowths forming pseudomorphs, which are easily recognized in thin section (Fig. 7, Supplementary Fig. S3). This observation is confirmed by powder XRD.

The glassy groundmass and microcrystalline phenocrysts are pictured in Fig. 7. Main rock forming minerals are $\mathrm{SiO}_{2}$ phases (see below), anorthite, indialite, mullite, hematite, magnetite, spinel (cf. Ciesielczuk et al. 2015, compare with Ciesielczuk et al. 2014). Neither corundum nor fayalite were detected (this mineral has been found in some iron-rich slags and in other Fe-rich melted combustion metamorphic rocks elsewhere in the world, cf. Sokol et al., 2002; Masalehdani et al. 2007; Novikova, 2009; Grapes, 2011; Grapes et al., 2011). An intriguing feature of this groundmass is the very irregular distribution of microcrysts at the millimeter scale: some areas contain only glass + anorthite, while some others are anorthitefree and contain glass, mullite and Fe-Al oxydes; this uneven distribution of the microcrysts and of the local scale microcryst/glass ratio may represent some inheritance of the original material being transformed upon partial melting. 
Textural inheritance is obvious in the former sand-sized detrital grains (Fig. 7a, c). Quartz was an important component of the initial waste material; it is slightly melted in Fig. 7a, almost fully melted in Fig. 7b, and recrystallized to $\mathrm{SiO}_{2}$ polymorph in Fig. 7c. Areas of a mineral of $\mathrm{SiO}_{2}$ composition (only $\mathrm{SiO}_{2}$ is detected by microprobe or $\mathrm{SEM}$ ) show a composite appearance: thin, slightly darker fibers are visible within a lighter area. The fibers are most likely cristobalite, within the quartz (and/or tridymite? Cristobalite is preferred with very high probability, because of trydimite being the structural analogue of nepheline always contains $\mathrm{K}, \mathrm{Na}, \mathrm{Al}$, and crystobalite is the first high temperature phase forming after quartz during its heating).

Mica is invariably transformed to mullite + glass with tiny spinel grains (Fig. 7d, e), while former detrital feldspar shows microscopic evidence of partial melting and recrystallization (Fig. 7f). Other minerals less frequently encountered and to be confirmed include orthopyroxene, sapphirine, gehlenite, larnite, melilite. XRD Rietveld counting shows that there is generally more hematite inside the prisms than outside (linked with the red colors inside and black colors outside?) although abundant and/or coarser-grained hematite has darker color (up to black). We finally note the high porosity of these rocks, which can be partly inherited from the parental material before melting, but also be the consequence of annealing process: when annealed, the sediments lose a significant amount of volatiles (water, $\mathrm{CO}_{2}$, volatile sulfur and nitrogen compounds, chlorine, etc.); this process entails a significant reduction in the initial volume of solid phases. As a result, before complete melting, the calcined rocks have high porosity. The presence of voids with convex rims implies that the matter around these was at least partially liquid.

\section{Chemical compositions}

Selected results of analyses are presented in Table 1 . Anorthite is actually a ternary feldspar containing some $\mathrm{K}_{2} \mathrm{O}$. The indialite (polymorph of cordierite) compositions compare well 
with those given by Gawęda et al. (2013) and Ciesielczuk et al. (2015); indialites invariably contain thin needles as inclusions, too thin to be analyzed. Hematite contains some $\mathrm{TiO}_{2}$; hercynite spinel is too small for analysis, but it could be the carrier phase of $\mathrm{Zn}$ in sample PAC3. Table 1 shows the composition of a ghost detrital muscovite now converted to mullite + glass; note the $\mathrm{K}_{2} \mathrm{O}$ loss with respect to that of a typical muscovite (10 wt\%). Results of analyses of the glassy matrix compare with those given by Gawęda et al. (2013) (70-75 wt\% $\mathrm{SiO}_{2}, 14-15 \mathrm{wt} \% \mathrm{Al}_{2} \mathrm{O}_{3}, 8-9 \mathrm{wt} \% \mathrm{~K}_{2} \mathrm{O}$, very little $\mathrm{Na}_{2} \mathrm{O}$ and $\mathrm{MgO}$ ). Assuming this composition represents a former silicate melt, and assuming the solids formed at high temperature contain little $\mathrm{K}_{2} \mathrm{O}$, a simple mass-balance calculation indicates that the paralavas $\left(4.5 \mathrm{wt} \% \mathrm{~K}_{2} \mathrm{O}\right)$ may have contained up to about 50-60\% melt fraction.

Fig. 8a shows two sets of results of EPMA analyses carried-out under the same conditions; a highly defocused beam (50 $\mu \mathrm{m}$ diameter spot) allows to capture the millimeterscale textural variations in this heterogeneous material, along two profiles (called profiles 4 and 5) each about one centimeter distance (PAC3 sample). Strong compositional gradients are visible at the millimeter scale in the distribution of major elements, while, at the handspecimen scale, whole rock compositions appear homogeneous. Both profiles correspond to distinct zones in the thin-section, and their compositions do not overlap.

Compositions recorded in profile 4 are close to the whole rock compositions for all major elements, except for $\mathrm{CaO}$ which is a little lower; these compositions are characterized by a large excess of alumina. In contrast, the compositions in profile 5 are less aluminous, and are distributed in the chemical space nearly continuously between two end-members as follows. (i) A Si-rich end-member, whose composition is glass-dominated $\left(75 \mathrm{wt} \% \mathrm{SiO}_{2}\right.$, $15 \mathrm{wt} \% \mathrm{Al}_{2} \mathrm{O}_{3}, 8-9 \mathrm{wt} \% \mathrm{~K}_{2} \mathrm{O}$, minor Fe, $\mathrm{Mg}, \mathrm{Ca}, \mathrm{Na}$ ). (ii) A Si-poor end-member, enriched in $\mathrm{Ca}$ and Fe with respect to the previous one, and when compared to the whole rock compositions; from the mineralogical point of view, this end-member corresponds to areas of 
millimeter size in which are preferentially concentrated anorthite (for $\mathrm{Ca}$ ) and / or magnetite and hematite (for Fe) crystals.

A remarkable aspect of the compositional variations displayed in profile 5 is that they do not distribute on both sides of the average whole rock composition, so they do not appear to be the result of a segregation between the liquid and the residue (or restite) of partial fusion: true restites would present an even higher $\mathrm{Al} / \mathrm{Si}$ ratio and a large excess of alumina as compared to the whole rocks. The chemical compositions are globally closer to that of liquids (their $\mathrm{Al}$ excess is reasonable) and we propose to interpret the local variations in the rock as a form of liquid-cumulate segregation, at the millimeter scale, occurring during solidification. In support of this idea, it is to be noted that the anorthite crystals are often concentrated at the rims of some bubbles, suggesting that they began to crystallize at the interface between two liquid phases, and continued to grow in the direction of the liquid. The increase in $\mathrm{Zn}$ from inside to rim is also conspicuous and will deserve a special discussion.

\section{Summary of mineralogy before and after partial melting}

Before (starting washed out mixture): quartz grains, feldspars, detrital muscovite, small fragments of shales, phyllosilicates (chlorite, kaolinite s.l., illite and smectites), possible ankerite and gypsum; magnetite is also possible as it was commonly used in coal laundries to weigh down the water and better separate the coal by flotation.

After (pyrometamorphic rock): glass of feldspathic composition (rich in $\mathrm{K}_{2} \mathrm{O}$ ), neogenic feldspar (anorthite and ternary feldspar), mullite, indialite, hercynite (Mg spinel was not observed), magnetite (Al-rich), relict quartz partly converted to a high-temperature $\mathrm{SiO}_{2}$ polymorph (cristobalite and/or tridymite). Minerals contributing to the formation of the liquid: the glass around the quartz and feldspar grains is clearly visible, it is probable that there is some with mullite in pseudomorphism of muscovite (Fig. 7e and detail 7f); in the matrix there are many microcrystals, but the glass is distinguished by its bluish luminescence. Apart from 
quartz and feldspar, the minerals that must have contributed to the formation of the glass must have been mainly illites (which provide $\mathrm{K}$ ) and possibly smectites ( $\mathrm{Na}, \mathrm{Ca}, \mathrm{Mg}$ ). $\mathrm{An}$ important (the main?) contributer to the combustion metamorphism silica-rich melts is the amorphous matter formed after dehydratation and dehydroxilation of hydromicas, which are the main constituent of any coal-bearing clayey rocks.

\section{Whole rock geochemistry: composition of paralavas}

A preliminary geochemical study was conducted on samples that were randomly selected on the heap, as well as on some prisms, in which sections were analyzed in order to document compositional variations between the core and the rim. Chemical profiles are represented in Fig. 8 b (see next section) and representative results of analyses are reported in Table 2, together with Stephanian rocks interbedded with the coal. In Fig. S4 and S5, equivalent rocks from Gawęda et al. (2013) and Ciesielczuk et al. (2014) are reported.

Gawęda et al. (2013) compare paralavas with magmatic rocks, namely andesites, on the basis of the relationships between $\mathrm{SiO}_{2}$ and $\mathrm{Na}_{2} \mathrm{O}+\mathrm{K}_{2} \mathrm{O}$. However, the comparison with andesites disregards the almost complete absence of $\mathrm{Na}_{2} \mathrm{O}$ in the paralavas, as well as their strongly peraluminous character (ASI -aluminum saturation index- > 2). Such a composition has no equivalent among magmatic rocks, even cumulates, and it compares better with those of clayrich siliclastic rocks, as advocated by Ciesielczuk et al. (2014) for coal wastes from the Starzykowiec dump (Silesia). The closest analogues may be anhydrous S-granites with high $\mathrm{Al}$ and $\mathrm{K}$.

In supplementary Figs S4 and S5, the chemical compositions of paralavas of our site are compared with those of sedimentary or volcano-clastic rocks (sandstones, shales and tuffs) of Stephanian age, which constitute the enclosing formations of the exploited coal measures, and that one would a priori expect to find as fragments in the heap. These compositions are also 
compared with compositions considered as representative of the liquid (now transformed to glass) obtained by microprobe analysis. The paralava compositions of our site do not show much variability (at the scale of our sampling set) and are in a first approach comparable to those of the Stephanian argillites. Specifically, the relative proportions of the main major elements $(\mathrm{Si}, \mathrm{Al}, \mathrm{Fe}+\mathrm{Mg})$ and the alumina excess (Al-Na-K-2Ca) are similar to those of shales (Fig. S4). Liquid compositions proposed by Gawęda et al. (2013), and the glass compositions analyzed in this study are much more siliceous and closer to alumina saturation, and they compare well to the liquids obtained by experimental melting of aluminous materials at low $\mathrm{P}_{\mathrm{H} 2 \mathrm{O}}$ (quartz - feldspar - mica mineral assemblages; Holtz and Johannes 1991; data and $\mathrm{T}-\mathrm{fO}_{2}$ path reconstructions are found in Grapes, 2011).

The chemical compositions of the paralavas suggest that they represent the result of insitu partial melting of a clay-rich protolith, without further displacement between the liquid and the solid (the conservation of texture is another argument). There is no important separate movement of the liquid (cf. the so-called fusion zone or zone refining process briefly discussed at the end of this paper); the possible subsequent solidification in the form of fingers (see below) does not involve any important melt movement (a limited flow of the partially cristallized melt will be proved by other evidence). However, the derivation of paralavas from argilites does not appropriately explain the relative abundance of $\mathrm{Ca}$, nor the presence in the paralavas of partially melted sand-sized grains of quartz and feldspar, too large to originate from argillites alone. It could be a dominantly clayey material containing a small sand fraction, but not abundant enough to significantly modify the Al / Si ratio of the mixture. In this hypothesis, the Ca content of the paralavas (1.8 to $2.0 \mathrm{wt} \%$ ) is a bit too high to be attributed to sand-sized plagioclase grains; alternatively, Ca could be derived from the tuffs interbedded within the Stephanian pile, from early diagenetic carbonates (ankerite) formed in the coal measures, or even from late diagenetic gypsum formed in the heap itself. Carbonates from the coal seams are the most common source of $\mathrm{Ca}$ for the melted rocks 
(about the contribution of carbonate precursor rocks into the combustion metamorphic rocks and the mineralogical diversity of the systems, see for example Sokol et al., 1998; Sokol, Nigmatulina and Volkova, 2002; Sokol and Volkova, 2007).

There remains the problem of (macroscopic) chemical homogeneity of the paralavas: since no single known country rock has exactly the required chemistry, it is likely that this homogeneity is the result of the artificial mixing of the waste particles as the gangue material of the coal is crushed and washed out before being discharged in the heap.

\section{Geochemical profiles across the prisms}

Three transverse profiles were performed across sectioned prisms (PAC1, 2, 3; each prism is cut in some five to ten samples, A, B, C...H, I, J), from the outside to the center, along a distance of ten to twenty centimeters. Each sample represents a volume of a few $\mathrm{cm}^{3}(3 \times 2 \times 1$ $\mathrm{cm})$, similar to a slice taken to prepare a thin-section. Observed compositional variations are shown in Fig. 8 b (selected results of analyses are given in Table 2, together with selected results of analyses for three other samples DR1, DR2 and DR3).

Major elements do not show very significant variations. The largest relative changes are in $\mathrm{CaO}( \pm 8 \%)$ but no spatial relationship in these variations is apparent. Among the analyzed trace elements, only $\mathrm{Zn}$, and to a lesser extent $\mathrm{Ga}$, show noticeable concentration gradients. $\mathrm{Zn}$ in particular varies over two orders of magnitude; in the rim of the prisms, the contents (> $500 \mathrm{ppm}$ ) are much higher than those of the host Stephanian clastic rocks, while in the core of the prisms, they appear to be very low $(<50 \mathrm{ppm}$, whereas $\mathrm{Zn}=95 \mathrm{ppm}$ in a typical claystone, cf. Li, 1981).

\section{Anisotropy of magnetic susceptibility}

AMS properties were studied on two prisms (PAC2 and PAC3; Fig. 9). Note in the PAC2 section an elliptical structure close to the center of the column (the column is incomplete 
here). In previous studies (Guy 2010), circular rings of this type in comparable situations have been described. These structures are not so rare but are difficult to characterize in thin-section: they are not marked by the presence of some minerals different from the surrounding material, but represent minute differences in texture, particularly the presence of very small circular voids, reminiscent of gas bubbles (cf. Bois, 2010, unpublished internship report, Ecole des Mines de Saint-Etienne).

The study of magnetic mineralogy through petrographic analysis of thin-sections and magnetic susceptibility $K$ versus temperature $T$ curves, $K(T)$, carried-out on the rocks analyzed for AMS shows that they are relatively poor in (titano-) magnetite and hematite. In addition, the average susceptibility that varies from $4.8310^{-4}$ to $1.9610^{-3}$ S.I. in PAC2 and from $1.9510^{-4}$ to $1.2610^{-3}$ S.I. in PAC3 remains moderate, in accord here with petrographic and $\mathrm{K}(\mathrm{T})$ curves observations.

The magnetic anisotropy is very low, the anisotropy parameter $\mathrm{P}$ is of the order of 1.01 (1\% anisotropy). In Fig. 10, hemispherical projections of the directions of the magnetic susceptibility axes $\mathrm{K}_{1}, \mathrm{~K}_{2}, \mathrm{~K}_{3}$ (equal area, lower hemisphere) are shown for the two analyzed samples; the $\mathrm{K}_{\mathrm{i}}$ 's represent the axes of the AMS ellipsoid (Bouchez 2000; Boiron 2011; Boiron et al. 2013) with $K_{1} \geq K_{2} \geq K_{3}$. There is a good gathering of the points, which was not a priori obvious in a context of very low anisotropy of magnetic susceptibility. The grouping is characterized by $\mathrm{K}_{3}$ (pole of the magnetic foliation) nearly vertical and $\mathrm{K}_{1}$ (magnetic lineation) that could fit with a flow direction, close to horizontal. The presence of a flow was not expected, since the partial melt formed by in-situ heating, and also solidified roughly on the spot, unlike the case of a melt in a conventional context of basalt columns, with a marked flow.

The direction of the movement of the melt, as it is also the case of basaltic flows, is not a priori consistent with the direction of the prisms; here the movement is roughly perpendicular to the prisms. The flow inside the heap can be understood if we note that the 
various layers deposited have a slope (Fig. 2a) that can lead to a movement; rock materials of similar type, particularly for their melting properties and coal content, are consistent with this "layering". Moreover, melting creates voids because of the high porosity of the whole heap, and the voids would gather in larger cavities when the solid portion is aggregated in a liquid during fusion, creating room for a flow by the action of gravity. On the whole, this may generate a limited but real flow by packing down toward altitudes located a bit lower compared to the initial situation in the heap (note that the local melting spots on natural or man-induced coal fires are connected with the outflow paths of hot gas jets, the so-called gas chimneys; in the same zones, the most intense redistribution of matter also occur, it includes the flow of melts, gas flow and gas transport synthesis and precipitation). The sections of the prisms studied here were not identified geographically (the prisms were not taken in-situ) and we therefore cannot indicate the flow directions in relation to the heap itself. In the case of the PAC2 sample, the long axis of the ellipse visible on the section corresponds to the flow direction given by $\mathrm{K}_{1}$.

Dispersion of the $\mathrm{K}_{1}$ axes can be analyzed according to two orders of organization: a first order corresponding to the mean direction of the $\mathrm{K}$ axis, and a second order indicating a dispersion around this value. This is particularly visible for $\mathrm{K}_{1}$ axes. If we compare to the mean flow direction, the $\mathrm{K}_{1}$ individual values can be discussed in terms of "disorganization" or "disorientation", in a context of weak anisotropy; if instead we refer to the hypothetical growth of fingers, we can talk of a second order organization that is to be found within the first order organization related to the flow. We may wonder whether the relatively small variations of this disorientation have a meaning, or whether they are only due to chance and non-interpretable. To answer this question would require more statistical studies. In this preliminary work, we merely note that a number of $\mathrm{K}$-axis directions (i.e. $\mathrm{K}_{1}$ axes; a more comprehensive study should consider the three axes, together with the shape parameters) do 
not seem to be related to chance, but instead that there is a correlation between the directions of $K_{1}$ and the positions in the column.

In order to reveal this organization, those results are synthesized in Fig. 11 representing the column sections together with the distribution of the analyzed portions. Inasmuch as the inclination of the $K_{1}$ axis is low, we have neglected it and, in the following discussion, we restrict ourselves to the study of the variation of $\mathrm{K}_{1}$ declination. And, because of the horizontality, all the data have been displayed inside the first quadrant by subtracting $180^{\circ}$ when the values plot in the third quadrant.

Commenting on all the values against each other would comprise a paper in itself. In Fig. 11a and b, we have used different colors as related to groups of $\mathrm{K}_{1}$ values. Fig. 11a, we have divided the data into two groups: one (blue) for the values above the average (the limit equally corresponds to the middle of the amplitude span by the data), and the other (green) for the data below the average. The two groups correspond to two parts of the analyzed prism: the blue data correspond to the sectors that include the principal direction of the flow, as preliminarily discussed above; and the green data correspond to the portion of the prism that is perpendicular to the previous sectors. Considering that we analyzed a limited portion of the prism (Figs 9c, e), we can imagine that the lacking points, corresponding to the portion of the prism that has not been analyzed, would plot among the green values. This would move the average of the directions $\left(74^{\circ}\right)$ toward lower values, and then make the average direction closer to the axis of the ellipse of $62^{\circ}$ (cf. Fig. $9 \mathrm{~b}$ ). This result strengthens the validity of the identity of the flow direction given by $\mathrm{K}_{1}$ and the axis of the ellipse. In Fig. 11b, we have shown an example of continuous variation of $\mathrm{K}_{1}$ values within column PAC3; the total variation runs along a $30^{\circ}$ span, from blue to red. The implications for the formation of the columnar structures are discussed below. Some additional data on specific spatial correlations between $\mathrm{K}_{1}$ values are reported in Fig. S6 and S7 (Supplementary material). 


\section{Columnar structures in paralavas: preliminary discussion}

\section{Solid/ liquid fraction in the paralavas}

The evidence presented above shows that there has always been a solid fraction in the paralavas. From a chemical and mineralogical point of view, paralavas are different from natural lavas (Sharygin et al. 1999; Sokol et al. 2002). Natural "lavas" may be completely melted but generally contain many solids in the form of phenocrysts (feldspars, pyroxenes etc.) and xenoliths (peridotites, granitic or metamorphic rocks from the basement). The rheological behavior of such an association is that of a liquid, up to solid proportions of 40 to $60 \%$ (e.g. Lejeune and Richet 1995; the more anhydrous melts that cristallize to paralavas may be more viscous that basaltic melts, Grapes et al.2011). The paralavas studied have passed through a state of (partial) fusion and their overall behavior resemble that of volcanic lava in its rheological properties: as stated above, let us remind the fluid textures quite analogous to those observed in lavas; the presence of visible glass under the microscope; the orientations of the magnetic susceptibility axes with signatures quite comparable to those observed during the flow of magmatic melts. Melt was even seen in situ (in a location different from the columns): during the quarrying operations, the machines that opened the heap encountered pockets of melt. Thus Mr. Lagrange (pers. com. 2000) speaks of “incandescent pockets of liquid magma, visible at night, a few meters in diameter, encountered once or twice in several places: 4 or 5 meters in diameter, the size of two cars, or a little more or a little less. The periphery of such liquid cores was very hot: several months of irrigation with water cannons $\left(20 \mathrm{~m}^{3}\right.$ / hour) were necessary to bring down the temperature before the exploitation could be carried out". The solidification and cooling of this melt, observed a few years before our own research, has not received any particular attention and was not studied.

In favor of a partial liquid state (if the presence of glass was not enough!), there are indirect arguments such as the estimation of the temperature that has been reached, by 
deciphering the texture of a metal chain affected by pyrometamorphism in the heap (the textures of the chain analyzed cannot be inherited from its manufacture; Supplementary material and Guy et al. 2001), or by the presence of $\mathrm{SiO}_{2}$ polymorphs (cristobalite / tridymite): $1370^{\circ} \mathrm{C}$ (chain), or even $1470^{\circ} \mathrm{C}$ (cristobalite, although the presence of this mineral cannot be a reliable proxy of ultra-high temperatures: it has been shown that it may form by a metastable mechanism and persist at $1,000^{\circ} \mathrm{C}$, Grapes et al. 2011). These are temperatures where one expects to find silicate melts. Under normal conditions, in areas affected by current combustion, the rocks of the heap remain very hot ("the jaws of the active shovels are often hot, they cannot be touched by hand", M. Lagrange, pers. com.). The gases released by the combustion and internal partial melting phenomena come out at temperatures of 300 to $600^{\circ} \mathrm{C}$, and, in the corresponding zones, $600^{\circ} \mathrm{C}$ is reached a few centimeters below the surface (Perrier Company, pers. com., 2000).

\section{Mechanism of formation of the columnar structure}

A major point of the discussion that follows concerns the structuration of the rocks encountered in the heap, which is similar to that observed in volcanic rocks (andesites, basalts, rhyolites etc.). We will not discuss the formation of columnar structures in volcanic rocks, which is the subject of an abundant bibliography (e.g. Noble Beard 1959; Long and Wood 1986; Goehring and Morris 2005; Kattenhorn and Schaefer 2008; Hetényi et al. 2012). One of the authors of the present paper discussed this issue and the reader will refer to Guy and Le Coze (1990) and Guy (2010). In these works we have shed new light on this question and have shown that two major classes of phenomena can be invoked to explain the structuring in columns, hereafter referred to as $\mathrm{H}_{1}$ and $\mathrm{H}_{2}$; and depending on the cases, they may both interplay (Guy 2010): $\mathrm{H}_{1}$ : thermal contraction of a cooling already solid mass that makes fractures develop (solidification mechanism is not studied); this phenomenon can play, but it cannot explain all the observed features, and we proposed as another candidate: $\mathrm{H}_{2}$ - the 
fingering of the solid during its growth within the liquid during solidification. In this case the solid mass is organized and its possible subsequent contraction upon cooling preferentially opens joints which were previously formed (Guy and Le Coze, 1990; Guy, 2010).

This phenomenon involves in a complex way the mechanism of constitutional supercooling. The latter is evoked during a competition between heat diffusion during the solidification of the silicate liquid, and molecular diffusion of chemical elements: these must migrate in the liquid from the interface with the solid (this is notably the case for volatiles such as $\mathrm{H}_{2} \mathrm{O}, \mathrm{CO}_{2}$, gases containing sulfur, chlorides, etc.). One speaks of constitutional supercooling because, within the play of these contrasted diffusions (the diffusion of heat is faster than that of the chemical elements), the temperature is below the melting temperature and liquid is still present (supercooling), for reasons related to the phenomenon itself (one speaks of "constitutional"). Under certain conditions, this phenomenon may give rise to the formation of prismatic cells, well-known to metallurgists (cf. Fig. 12). When considering water-rich (or other volatile) media, rather than dry media, the diffusion coefficients of the elements in the magmatic liquid are close to those observed in metallurgical liquids (Guy and Le Coze, 1990 and references therein). The discussion on thermal gradients specific for combustion metamorphic rocks can be found in Burg et al. (1991), for the Hatrurim formation, as well as in Sokol and Volkova (2007).

\section{Field observations}

Field observations are helpful to clarify certain points. In particular, contrarily to what is found in natural basaltic bodies, prisms of the heap reveal between them large irregular vertical or horizontal voids as discussed previously (Figs 2d-f); in the case of the vertical voids, the concavities of the adjacent faces do not match and the prisms do not perfectly fit into each other. The surfaces opened to the voids are not smooth but have a "lumpy" nature; 
as if melt had frozen (some sublimate minerals are also present on their surfaces, such as sulfur).

As a tentative explanation, we can imagine that the fusion affected unconsolidated blocks leaving between them a high porosity; the growth of the solid has collected the mineral matter and created voids between the digitations: these did not meet because the matter was lacking for more solid growth. It is also possible (but perhaps less likely because of the low viscosity of the dry peraluminous melts) that the occasional emptying of the liquid through the porous parts (not subject to combustion and fusion) underlying the melting zone may open voids: the liquid between them, that escaped, left some pustules on the prism surfaces. For one reason or another, the prisms are not welded together. The observation of pustules on the faces of the columns inside vertical voids (Fig. 3c) is an important point: how can one account for the development of such pustules if the faces of the columns are open by thermal contraction once all the melt has been solidified with no liquid left? On the contrary, the opening of voids in the course of solidification and the very development of solid fingers better reflects the pustule occurrences. This interpretation is not consistent with $\mathrm{H}_{1}$ and favors $\mathrm{H}_{2}$.

Other factors must be taken into account to understand the formation of these prisms and their characters: - the liquid has not been brought in from an external source (it did not flow for a long distance) and has been created in-situ, the heat source being present in the rock itself; - the redox regime is not that most often found in ordinary volcanic rocks: the melting is accompanied by oxidation under surficial conditions and the phenomenon evolves towards reduction (carbon combustion, increase in $\mathrm{CO}_{2}$, decrease in $\mathrm{O}_{2}$ partial pressures); the columns are red, and their border is sometimes gray / black (Figs 3c, 9d); this is the inverse of the standard situation for basaltic magmas which are brought up in a reduced state from the mantle depths: in this case gray / black rocks can oxidize at their periphery due to weathering under surficial conditions (possible red peripheries). The black rim of the prisms observed in 
the heap is another argument for early structure before complete solidification $\left(\mathrm{H}_{2}\right)$ inasmuch as late weathering could not result in a black border (if we had $\mathrm{H}_{1}$ ). XRD Ritveld data locally indicate the relatively lesser abundance of hematite in the periphery as compared to the center of the prisms, although we cannot make it a general rule (in some other places, the darker zones may contain more hematite than in red zones impregnated by hematite powder). As we have seen, the columns sometimes stopped their formation before they fully merged, which resulted in vertical voids (Fig. 2e); as an additional character, the concavities of their faces are sometimes turned inward (Fig. 3). It seems that this can again be explained in the frame of hypothesis $\mathrm{H}_{2}$ : growing fingers can be festooned, with indifferent outward or inward face concavity, also corresponding to a step previous to the meeting of adjacent fingers and the formation of straight joints (this festooning and concavity change of the circular structures is only rarely observed in basaltic columns, when growing rings are visible inside the fingers, cf. Guy, 2010).

\section{Whole-rock geochemistry}

Geochemical variations across the column sections observed above are not to be related to a weathering process that would occur after the complete solidification of the rocks has taken place: we have no petrographic evidence for such weathering, that would, from a geochemical point of view, lead to a partial leaching of $\mathrm{CaO}$ and an increase in the loss on ignition: in fact, the SEM observations indicate that $\mathrm{CaO}$ is hosted by micrometric crystals of anorthite, a mineral particularly sensitive to surface alteration, that should be argillized if the rock had been seriously affected by atmospheric precipitates (in weathered rocks Ca could be immobilized in Ca silicate hydrates, Ca carbonates, Ca sulphates, but none of these minerals seems to be present in sufficient quantity, and the loss on ignition would then be increased, which is not the case). As the rocks are very poor in $\mathrm{Na}_{2} \mathrm{O}$, it is not expected here to observe a 
significant leaching of this element. There is no apparent change in the porosity of the rocks from inside to outside the prisms.

Furthermore, the changes observed for $\mathrm{Zn}$ are not limited to the periphery of the columns (a few millimeters) but show a gradient from inside to outside of the sections over about $20 \mathrm{~cm}$ distance. As we have not identified specific $\mathrm{Zn}$ carrier minerals in the outer parts of the column (that are richer in this element), it is difficult to interpret the $\mathrm{Zn}$ gradient as a late filling by condensate minerals related to the movement of hot gases (we cannot rule out a two-phase melt in which early gases are present; but there is still melt that allows for the digitations to continue growing). No change in the porosity of the rock has been observed from inside to outside of the prisms.

As the results of the AMS study also show (as well as the remarkable presence of a protected ring in the center of the column), we are facing a cylindrical symmetrical structure affecting the entire section of the column. This is consistent with the growth of the solid finger advancing in the melt (cf. Guy, 2010). During the constitutional supercooling mechanism, some elements are expelled from the solid during the liquid $\rightarrow$ solid process. The movement of the chemical elements is due to a local diffusion process and does not need any melt flow (that may happen in addition at the larger scale of the mass of paralava, due to external conditions). We postulate that, as in the case of rocks we have studied elsewhere (basalts), it is mainly the expulsion of volatiles which is preferred over that of other chemical elements. Volatiles which can be expected include gas compounds such as $\mathrm{H}_{2} \mathrm{O}, \mathrm{CO}_{2}$, and elements such as $\mathrm{Cl}, \mathrm{F}$, and $\mathrm{S}$, which elements are found in the efflorescences at the surface of the heap (e.g. salammoniac for $\mathrm{Cl}$ ). Basaltic magmas forming deep in the crust under high water pressure, we can think of the dominant role of $\mathrm{H}_{2} \mathrm{O}$ in that case; by contrast, it seems that in the case of the studied paralavas, we can think of a more important role of $\mathrm{Cl}$ (that is also more abundant in the system, as associated to coal). Chlorine acting as a ligand for 
certain metal elements such as $\mathrm{Zn}$ could then lead, during the solidification of the columns, to an increase of the content from inside to outside.

We may compare this behavior to that observed in A-type granites (Johannes and Holtz 1990), formed in superficial regions of the crust and relatively poor in water: enrichments in $\mathrm{Zn}$ have been observed in evolved terms, and these have been connected with the specific role of $\mathrm{Cl}$ relative to $\mathrm{H}_{2} \mathrm{O}$. In the rocks of the present study, the increase in $\mathrm{Zn}$ content is not accompanied by specific Zn-bearing minerals (these have not been found yet). In contrast, the most important role of $\mathrm{H}_{2} \mathrm{O}$ in the case of solidification of basalts explains why the chemical variations transverse to the prisms are in this case very low and generally invisible, as water does not have the same capacity as $\mathrm{Cl}$ to associate with metal elements. Water remains the main component in fumarolic gases generated by coal combustion for the simple reason that water, like $\mathrm{CO}_{2}$, are two coupled main products of coal oxidation. Water is the main component of fluid inclusions in any combustion-metamorphic related fumarolic minerals. One can speaks about the relative role (or activity) of $\mathrm{Cl}$, which really might be locally high. Whatever the mechanism (the previous interpretation is of a preliminary nature; the behavior of $\mathrm{Zn}$ in gas-transport, namely chemical vapor deposition, processes should be considered), we can speak of a chemical differentiation process accompanying the solidification from the inside to the outside. The minute enrichment in $\mathrm{Al}$ relative to $\mathrm{Si}$ sometimes observed between the center and the periphery of the column might be another possible mark of this differentiation? Gaweda et al. (2013) also observed segregation within the magmas from which the paralavas were derived.

\section{Anisotropic magnetic susceptibility of the paralava}

Summarizing the different results obtained in the AMS study, we recognize different situations. (i) Some values of the declinations are very close for points along the same radii with respect to the symmetry of the column section. (ii) AMS directions have more broadly 
the same values for groups of points in the same circular sectors, and contrasting values for directions in other sectors. (iii) Variations of the directions are correlated when moving along a circular ring around the center of the column.

The ring structures such as the ellipse noticed on PAC2 section are not explainable by an operation that would develop from the edges of the already solid columns, e.g. weathering. They rather agree with the possible formation of the columns by fingering during solid growth within the liquid. In the case of the PAC2 sample, the first axis of the ellipse corresponds to the flow direction given by $\mathrm{K}_{1}$. The a priori circular structure of the finger has been deformed into an ellipse by the action of the flow. In this context, the disorganization of the main direction of the flow can be explained in different ways (Supplementary Fig. S8.): - by a mechanical action, minerals already formed within the liquid seeing their orientation slightly modified by the contact with the fingering solid (Fig. S8a); - by the orientation of the last mineral to crystallize being imposed by that of the finger, whether these minerals are organized by epitaxial growth perpendicularly or parallel to the structure (Fig. S8b, c and d.). In these cases, this is a second order effect, AMS anisotropy is very low as we have said above; AMS provides information here on the last steps of solidification.

Such second order orientations occur at all depths inside the column and respect to the cylindrical symmetry (within the limits of our study that does not have a statistical meaning). It seems difficult, if not impossible, to believe that the possible final fracturing of the solid, if any, forming joints limiting the columns, could change the $\mathrm{K}$ axis directions in such a pervasive and organized manner; this would require that disorientation selectively occurs in certain directions and not others. We also noted the possible absence of any fracturing, columns ending without reaching each other and therefore without breaking afterwards to demarcate their contours.

If all the points analyzed in the sections of the columns do not show distributions of values in clear relationship with their position, we believe that the results highlighted here do 
not come by chance (the distribution of points in PAC2 - sharing between the blue and green groups- has in itself a statistical significance). These results, which match with those of the geochemical study, preferentially agree with the fingering hypothesis.

\section{Conclusions}

In the literature on paralavas, the columnar jointing phenomenon does not seem to have been observed; here it shows a remarkable extent and is probably one of the few worldwide occurrences. Flow textures have already been described within paralavas (Sokol 2005; Masalehdani et al. 2007; Grapes 2011), with "stalactites" as well as paralava veins. However, it seems that such columnar structures have never been described in such a context. The reasons for the occurrence of columnar structure here are not known; they may relate to the size of the slag heap, the notable abundance of coal remains providing sufficient energy by combustion, and the size and location of the molten zone sufficiently buried for low thermal gradients (favouring the phenomenon of supercooling) to prevail.

In some cases, columns (centimeter to decimeter size) within burnt and partially melted sediments (sandstones, shales), and with a mineralogy sometimes similar to that of the paralavas, have been described close to basaltic necks (Spry and Solomon 1964, and others). The mechanism of column formation in that case may be debatable (contraction cracks like in the case of well-known dried mud, and/or fingering by supercooling process; note that the inward concavity of some of the columns described in Spry and Solomon (1964) resembles what we have described in Figs 2, 3 and 5, questioning the thermal contraction hypothesis in that case), but these occurrences do not correspond to paralavas, as in the present study: there the rocks subjected to melting are "standard" natural rocks, with properties of homogeneity both from textural and chemical points of view (sandstones, claystones). Called buchites, they originate from contact metamorphism of natural sedimentary rocks by an external heat source provided by the volcanic rock, and not from phase transformations inside a burning coal heap. 
In the phenomenon described here, the melting and solidification are happening roughly in the same place (unlike the case of basalts). The situation is similar to what is described in the literature (metallurgy, ceramics) as zone melting or zone refining (e.g. Sayir and Farmer 2000; LLorca and Orera 2006; Ren et al. 2016), see Fig. 13. At the melt front, new material is added to the melt pocket when the temperature rises enough, whereas at the back material is extracted from the melt by solidification. This leads to fractionation of species that prefer the melt vs. those that prefer the solid, as well as between volatile vs. refractory species. The compositions of melt, solids (refractory or solidified) and volatiles will vary with the inhomogeneity of the heap.

We have not discussed the possibility that chemical differentiation can also take place during partial melting, not just during solidification. One may think however that the final solidification phenomenon is responsible for the observed structure, because the scale at which it occurs is not the same (Supplementary Fig. S9): the area subjected to melting and moving within the heap may have several meters to tens of meters of amplitude, while the columnar structures are a few centimeters to decimeters in size, and the chemical differentiation during partial melting takes place at millimeter scale. However, the two phenomena may be coupled to the extent that the zone refining process can ensure a prior enrichment of the (partially) molten zone in some chemical components (we have discussed the case of volatiles, especially $\mathrm{Cl}$ ) and enhance the formation of the supercooling process (this last process may not occur immediately, but operate only for systems that have exceeded a certain size).

Finally, it appears that burning heaps are very interesting features and are truly anthropic analogues - hence the names "anthropogenic pyrometamorphism” (Grapes, 2011) and "parabasalts" (Sharygin et al. 1999) - of some volcanic phenomena, at least for the solidification process. It is thus worth noting that locally, the present heap is known as the "Ricamarie volcano". 


\section{Acknowledgments}

The authors express their thanks to Pierre Alexis Chaboche, Stéphanie Pigeron, Romain Cador, Jordan Ré-Bahuaud, Jean-Yves Cottin, René-Pierre Menot and Pascal Richet who have contributed to the matters presented in the paper by discussion and/or by their encouragement to pursue this research. The comments by the reviewers and editors helped to improve the manuscript. Major thanks are due to Justyna Ciesielczuk and Ella Sokol whose detailed constructive comments was of great benefit.

\section{References}

Boiron T (2011) Etude multi-échelle des variations structurales, géochimiques et des propriétés magnétiques des coulées basaltiques prismées : exemple de la coulée de La Palisse (Ardèche) et de Saint-Arcons d'Allier (Haute-Loire). PhD thesis, École des Mines de Saint-Étienne

Boiron T, Bascou J, Camps P, Ferré EC, Maurice C, Guy B, Gerbe MC, Launeau P (2013) Internal structure of basalt flows: Insights from magnetic and crystallographic fabrics of the La Palisse volcanics, French Massif Central. Geophys J Int 193: 585-602

Bouchez JL (2000) Magnetic susceptibility anisotropy and fabrics in granites. Comptes Rendus Acad Sci Ser. II Fasc.a 330: 1-14

Burg A, Starinsky A, Bartov Y and Kolodny Y (1991) Geology of the Hatrurim formation ("mottled zone") in the Hatrurim basin. Israel Journal of Earth Sciences 40: 107-124

Carpentier O, Defer D, Antczak E, Duthoit B (2005) The use of infrared thermographic and GPS topographic surveys to monitor spontaneous combustion of coal tips. Appl. Therm. Eng. 25: 2677-2686 
Chakravarty S, Mohanty A, Banerjee A, Tripathy R, Mandal GK, Basariya MR, Sharma M (2015) Composition, mineral matter characteristics and ash fusion behavior of some Indian coals. Fuel 150: 96-101

Chenevoy M (1971) Notice explicative de la carte géologique à 1/50 000 Saint-Étienne. Editions du BRGM, Orléans, 20 pp

Chesnokov BV, Tsherbakova EP (1991) The mineralogy of burned heaps in the Chelyabinsk coal basin. Publ. H. Nauka, Moscow

Ciesielczuk J (2015) Coal mining and combustion in the coal waste dumps of Poland. In: Stracher GB, Sokol E, Prakash A (eds.), Coal and peat fires: a global perspective. Elsevier, Boston, pp 463-473

Ciesielczuk J, Kruszewski Ł, Majka J (2015) Comparative mineralogical study of thermallyaltered coal-dump waste, natural rocks and the products of laboratory heating experiments. Int J Coal Geol 139: 114-141

Ciesielczuk J, Misz-Kennan M, Hower JC, Fabiańska MJ (2014) Mineralogy and geochemistry of coal wastes from the Starzykowiec coal-waste dump (Upper Silesia, Poland). Int J Coal Geol 127: 42-55

Creelman RA, Ward CR, Schumacher G, Juniper L (2013) Relation between coal mineral matter and deposit mineralogy in pulverized fuel furnaces. Energy and Fuels 27: 57145724

Deer WA, Howie RA, Zussman J (2013) An introduction to the rock forming minerals. $3^{\text {rd }}$ excerpted student edition. Geological Society of London, UK, 505 pp

Esbensen, KH (2020) Introduction to the theory and practice of sampling. IM Publications Open LLP, Chichester UK, 323 pp

Fabiańska MJ, Ciesielczuk J, Kruszewski Ł, Misz-Kennan M, Blake DR, Stracher G, Moszumańska I (2013) Gaseous compounds and efflorescences generated in self- 
heating coal-waste dumps - A case study from the Upper and Lower Silesian Coal Basins (Poland). Int J Coal Geol 116-117: 247-261

Fermor LL (1914) On the geology and coal resources of Korea State Central Provinces.

Memoirs of the Geological Survey of India 41 (2): 148-245

Fettes D, Desmons J editors (2011) Metamorphic rocks: a classification and glossary of terms. Recommendations of the International union of geological sciences (IUGS), Subcommission on the systematics of metamorphic rocks. Cambridge University Press, Cambridge UK, 258 pp

Gawęda A, Janeczek J, Kierepka M, Kądziołko-Gaweł M, Krzykawski T (2013) Indialite-rich paralava from a coalmine waste-dump, Sosnowiec, Poland. Neues Jahrb für Mineral Abhandlungen J Mineral Geochemistry 190: 237-251

Gawęda A, Kierepka M, Janeczek J, Mazur-Cuber A (2011) Paralava from coal-dump combustion in Upper Silesia, Poland: melt separation leaving a cordierite-rich restite. In: Broekmans MATM (editor): Proceedings of the $10^{\text {th }}$ International congress for applied mineralogy (ICAM), 01-05 August 2011, Trondheim, Norway. Springer, Berlin Heidelberg, pp 221-227

Goehring L, Morris SW (2005) Order and disorder in columnar joints. Europhys Lett 69: $739-745$

Grapes R (2011) Pyrometamorphism. Springer, 365 pp

Grapes R, Korzhova S, Sokol E, Seryotkin Y (2011) Paragenesis of unusual Fe-cordierite (sekaninaite)-bearing paralava and clinker from the Kuznetsk coal basin, Siberia, Russia Contrib Mineral Petrol 162: 253-273

Grapes R, Zhang K, Peng ZL (2009) Paralava and clinker products of coal combusion, Yellow River, Shanxi Province, China. Lithos 113: 831-843 
Guy B (2010) Comments on "Basalt columns: large scale consitutional supercooling?” (J Volcanol Geotherm Res 184, 2009, 347-350) by John Gilman, and presentation of some new data. J Volcanol Geotherm Res 194: 69-73

Guy B, Le Coze J (1990) Réflexions sur la prismation des basaltes: l'instabilité du front plan de solidification. Comptes Rendus l'Académie des Sciences, Paris 311: 943-949

Guy B, Garcia D, Le Coze J, Theisse V (2001) Estimation de la température atteinte dans le crassier Saint-Pierre de la Ricamarie (Loire) à partir de l'observation de textures d'oxydation / fusion / solidification dans un élément de chaîne métallique prélevé sur le site. "3 Pas, Ricamarie cote 640" Les Cahiers de la Rotonde, Publications de l'Université de Saint-Etienne et de l'Ecole n. s. des mines de Saint-Etienne, pp 61-69

Hetényi G, Taisne B, Garel F, Médard É, Bosshard S, Mattsson HB (2012) Scales of columnar jointing in igneous rocks: Field measurements and controlling factors. Bull Volcanol 74: 457-482

Holtz F, Johannes W (1991) Genesis of peraluminous granites I. Experimental investigation of melt compositions at 3 and $5 \mathrm{~kb}$ and various $\mathrm{H}_{2} \mathrm{O}$ activities. J Petrol 32: 935-958 JohannesW, Holtz F (1990) Formation and composition of $\mathrm{H}_{2} \mathrm{O}$-undersaturated granitic melts. In: High temperature metamorphism and crustal anatexis, Ashworth and Brown editors, Unwin Hyman, pp 87-104

Humphries DW (1992) The preparation of thin sections of rocks, minerals and ceramics. Royal Microscopical Society, Oxford Science Publications, Microscopy Handbooks 24, $83 \mathrm{pp}$

Johari I, Said S, Hisham B, Bakar A, Ahmad ZA (2010) Effect of the change of firing temperature on microstructure and physical properties of clay bricks from Beruas (Malaysia). Sci Sinter 42: 245-254

Karaman S, Ersahin S, Gunal H (2006) Firing temperature and firing time influence on mechanical and physical properties of clay bricks. J Sci Ind Res (India) 65: 153-159 
Kattenhorn SA, Schaefer CJ (2008) Thermal-mechanical modeling of cooling history and fracture development in inflationary basalt lava flows. J Volcanol Geotherm Res 170: $181-197$

Kruszewski $Ł$ (2013) Supergene sulphate minerals from the burning coal mining dumps in the Upper Silesian Coal Basin, South Poland. Int J Coal Geol 105: 91-109

Kurz W, Fisher DJ (1989) Fundamentals of solidification, third revised edition. Trans Tech Publications, Aedermannsdorf $\mathrm{CH}, 306 \mathrm{pp}$

Lapham DM, Barnes JH, Downey WF and Finkelman RB (1980) Mineralogy associated with burning anthracite deposits of eastern Pennsylvania. Pennsylvania Geological Survey, Mineral Resources Report 78, 82 pp

Lejeune A, Richet P (1995) Rheology of crystal bearing silicate melts: an experimental study at high viscosities. Journal of Geophysical research 100: 4215-4229

LI Y-H., 1981. Ultimate removal mechanisms of elements from the ocean. Geochim. Cosmochim. Acta 45: 1659-1664

Liu B, He Q, Jiang Z, Xu R, Hu B (2013) Relationship between coal ash composition and ash fusion temperatures. Fuel 105: 293-300

LLorca J, Orera VM (2006) Directionally solidified eutectic ceramic oxides. Prog Mater Sci 51: 711-809

Long PE, Wood BJ (1986) Structures, textures, and cooling histories of Columbia River basalt flows (USA). Geol Soc Am Bull 97 (9): 1144-1155

Masalehdani MNN, Black PM, Kobe HW (2007) Mineralogy and petrography of iron-rich slags and paralavas formed by spontaneous coal combustion, Rotowaro coalfield, North Island, New Zealand. Rev Eng Geol 28: 117-131

Masalehdani MNN, Mees F, Dubois M, Coquinot Y, Potdevin JL, Fialin M, Blanc-Valleron MM (2009) Condensate minerals from a burning coal-waste heap in Avion, Northern France. Can Mineral 47: 573-591 
Masalehdani MNN, Paquette Y (2013) Coal Fires of Northern and Massif Central, France. In: Coal and peat fires: a global perspective. Elsevier Boston, 121-136

Matjie RH, Ward CR, Zhongsheng L (2012) Mineralogical transformations in coal feedstocks during carbon conversion, based on packed-bed combustor tests: part 1. Bulk Coal and Ash Studies. Coal Combust Gasif Prod 4: 45-57

Mattson HB, Carichi L, Almqvist B, Caddick M, Bosshard S, Hetenyi G, Hirt A (2010) Melt migration in basalt columns driven by crystallization-induced pressure gradients, Nature Communications, DOI: 10.1038/ncomms1298, 8 pp

Misz-Kennan M, Fabiańska MJ (2011) Application of organic petrology and geochemistry to coal waste studies. Int J Coal Geol 88: 1-23

Nichol D, Tovey NP (1998) Remediation and monitoring of a burning coal refuse bank affecting the Southsea Looproad at Brymbo, North Wales. Eng Geol 50: 309-318

Noble Beard C (1959) Quantitative study of columnar jointing. Geol Soc Am Bull 70: 379_ 382

Novikova SA (2009) Fayalite from Re-rich paralavas of ancient coal fires in the Kuzbass, Russia, Geology of ore deposits 51 (8): 800-811

Nyssen J, Vermeersch D (2010) Slope aspect affects geomorphic dynamics of coal mining spoil heaps in Belgium. Geomorphology 123: 109-121

Papike JJ (1987) Chemistry of the rock-forming silicates: Ortho, ring, and single-chain structures. Reviews of Geophysics 25 (7): 1483-1526

Pouchou JL, Pichoir F (1991) Quantitative analysis of homogeneous or stratified microvolumes applying the model 'PAP'. In: Heinrich KFJ, and Newbury DE (editors): Electron probe quantitation. Plenum Press, New York, pp 31-75

Quintero JA, Candela SA, Ríos CA, Montes C, Uribe C (2009) Spontaneous combustion of the Upper Paleocene Cerrejón Formation coal and generation of clinker in La Guajira Peninsula (Caribbean Region of Colombia). Int J Coal Geol 80: 196-210 
Ren Q, Su H, Zhang J, Yao B, Ma W, Liu L, Fu H, Huang T, Guo M, Yang W (2016) Solidliquid interface and growth rate range of $\mathrm{Al}_{2} \mathrm{O}_{3}$-based eutectic in situ composites grown by laser floating zone melting. J Alloys Compd 662: 634-639

Ribeiro J, Suárez-Ruiz I, Ward CR, Flores D (2016) Petrography and mineralogy of selfburning coal wastes from anthracite mining in the El Bierzo Coalfield (NW Spain). Int J Coal Geol 154-155: 92-106

Sayir A, Farmer SC (2000) The effect of the microstructure on mechanical properties of directionally solidified $\mathrm{Al}_{2} \mathrm{O}_{3} / \mathrm{ZrO}_{2}\left(\mathrm{Y}_{2} \mathrm{O}_{3}\right)$ eutectic. Acta Mater 48: 4691-4697

Sharygin VV, Sokol EV, Nigmatulina EN, Lepezin GG, Kalugin VM, Frenkel AE (1999) Mineralogy and petrography of technogenic parabasalts from the Chelyabinsk browncoal basin. Russ Geol Geophys 40: 879-899

Skarżyńska KM (1995) Reuse of coal mining wastes in civil engineering, Part 1: Properties of minestone. Waste Manag 15: 3-42

Sokol E (2005) Combustion metamorphism (in Russian with English introduction and figure captions). Publishhing house of the Siberian branch of Russian Academy of Sciences, Novosibirsk

Sokol EV, Nigmatulina EN, Volkova NI (2002) Fluorine mineralization from burning coal spoil-heaps in the Russian Urals. Mineral Petrol 75: 23-40

Sokol EV, Sharygin V, Kalugin VM, Volkova NI, Nigmatulina EN (2002) Fayalite and kirschsteinite solid solutions in melts from burned spoil-heaps, South Urals, Russia. Eur J Mineral 14: 795-807

Sokol E, Volkova N, Lepezin G (1998) Mineralogy of pyrometamorphic rocks associated with naturally burned coal-bearing spoil-heaps, Chely-abinsk coal basin, Russia. Eur J Miner 10 (5): 1003-1014 
Sokol EV, Volkova NI (2007) Combustion metamorphic events resulting from natural coal

fires. In: Stracher G (ed), Geology of Coal Fires: Case Studies from Around the World,

Geological Society of America Reviews in Engineering Geology XVIII, 97-115

Spry AH, Solomon M (1964) Columnar buchites at Apsley, Tasmania. Q J Geol Soc London 120: $519-545$

Stefanescu DM, Ruxanda R (2004) Fundamentals of solidification. Metallography and Microstructures. ASM Handbook 9 (4): 71-92

Thiéry V, Guy B (2015) Some aspects of petrography of burnt colliery spoil, in: Çopuroğlu, O. (Ed.), Proceedings of the $15^{\text {th }}$ Euroseminar on Microscopy Applied to Building Materials. Delft, pp 71-76

Thiéry V, Guy B, Kruszewski Ł and Carpentier J F (2018) The burning coal heap at La Ricamarie, Loire Coal Basin, France. In: Stracher G B (ed): Coal and peat fires: a global perspective. Volume 5: case studies - advances in field and laboratory research, pp 301331

Ward CR (2016) Analysis, origin and significance of mineral matter in coal: an updated review. Int J Coal Geol 165: 1-27

Whitney DL, Evans BW (2010) Abbreviations for names of rock-forming minerals. American Mineralogist 95: 185-187

Witzke T, de Wit F, Kolitsch U, Blaß G (2015) Mineralogy of the burning Anna 1 coal mine dump, Alsdorf Germany. In: Coal and peat fires: a global perspective. Volume 3: Case studies-coal fires, pp 203-240

Žáček V, Skála R (2015) Mineralogy of Burning-Coal Waste Piles in Collieries of the Czech Republic. In: Stracher GB, Sokol E, Prakash A (eds.), Coal and peat fires: a global perspective. Elsevier Boston, pp 109-159 
Žáček V, Skála R, Dvořák Z (2015) Combustion metamorphism in the Most basin, Czech Republic. In: Stracher G, Prakash A, Sokol EV (eds.), Coal and peat fires: a global perspective. Volume 3: Case studies - coal fires, pp 161-202

Zio E, Aven T (2013) Industrial disasters: Extreme events, extremely rare. Some reflections on the treatment of uncertainties in the assessment of the associated risks. Process Saf Environ Prot 91: 31-45 


\section{Tables}

\begin{tabular}{|c|c|c|c|c|c|c|c|c|c|c|}
\hline Sample & DR2A & PAC3 & DR2A & PAC3 & PAC3 & PAC3 & DR2A & DR2A & PAC3 & PAC3 \\
\hline Spot & 12 & 27 & 5 & 22 & 19 & 20 & 14 & 7 & 25 & 26 \\
\hline Mineral & \multicolumn{2}{|c|}{ An } & \multicolumn{2}{|c|}{ Ind } & \multicolumn{2}{|c|}{ Mag } & Ms & \multicolumn{3}{|c|}{ Glass matrix } \\
\hline \multicolumn{11}{|c|}{ Main oxide contents [wt\%] } \\
\hline $\mathrm{Na}_{2} \mathrm{O}$ & 0.65 & 0.70 & 0.12 & 0.10 & 0.02 & 0.00 & 0.18 & 0.37 & 0.37 & 0.37 \\
\hline $\mathrm{K}_{2} \mathrm{O}$ & 0.45 & 0.86 & 1.99 & 1.95 & 0.03 & 0.04 & 3.42 & 7.99 & 8.93 & 8.51 \\
\hline $\mathrm{MgO}$ & 0.04 & 0.09 & 10.55 & 9.78 & 0.58 & 0.66 & 0.09 & 0.09 & 0.23 & 0.17 \\
\hline $\mathrm{CaO}$ & 17.96 & 16.57 & 0.15 & 0.08 & 0.09 & 0.00 & 0.48 & 0.84 & 0.08 & 0.48 \\
\hline $\mathrm{MnO}$ & 0.06 & 0.09 & 0.36 & 0.58 & 0.55 & 0.53 & 0.03 & 0.06 & 0.05 & 0.01 \\
\hline $\mathrm{ZnO}$ & 0.06 & 0.03 & 0.00 & 0.06 & 0.19 & 0.07 & 0.00 & 0.01 & 0.03 & 0.00 \\
\hline $\mathrm{FeO}^{\mathrm{T}} *, \mathrm{Fe}_{2} \mathrm{O}_{3}{ }^{\mathrm{T}}$ & 0.33 & 0.68 & 2.35 & 6.06 & 88.14 & 88.62 & 2.36 & 0.83 & 0.78 & 0.65 \\
\hline $\mathrm{TiO}_{2}$ & 0.05 & 0.03 & 0.26 & 0.15 & 2.14 & 1.99 & 0.35 & 0.76 & 0.32 & 0.33 \\
\hline $\mathrm{Al}_{2} \mathrm{O}_{3}$ & 33.74 & 32.43 & 31.42 & 29.32 & 5.99 & 6.29 & 40.02 & 14.08 & 15.31 & 14.19 \\
\hline $\mathrm{SiO}_{2}$ & 46.16 & 47.69 & 52.65 & 49.96 & 0.37 & 0.33 & 52.17 & 74.42 & 70.41 & 73.71 \\
\hline Total & 99.50 & 99.15 & 99.85 & 98.05 & 98.32 & 98.64 & 99.08 & 99.45 & 96.47 & 98.46 \\
\hline \multicolumn{11}{|c|}{ Numbers of cations in atoms per formula unit [apfu] } \\
\hline $\mathrm{Na}$ & 0.06 & 0.07 & 0.02 & 0.02 & & & 0.02 & & & \\
\hline $\mathrm{K}$ & 0.02 & 0.05 & 0.25 & 0.26 & & & 0.27 & & & \\
\hline $\mathrm{Mg}$ & 0.00 & 0.00 & 1.57 & 1.51 & 0.03 & 0.04 & 0.02 & & & \\
\hline $\mathrm{Ca}$ & 0.89 & 0.82 & 0.01 & 0.01 & & & 0.03 & & & \\
\hline $\mathrm{Mn}$ & 0.00 & 0.00 & 0.03 & 0.05 & 0.02 & 0.02 & 0.00 & & & \\
\hline $\mathrm{Zn}$ & 0.00 & 0.00 & 0.00 & 0.00 & 0.01 & 0.00 & 0.00 & & & \\
\hline $\mathrm{Fe}$ & 0.01 & 0.02 & 0.19 & 0.53 & 2.42 & 2.41 & 0.12 & & & \\
\hline $\mathrm{Ti}$ & 0.00 & 0.00 & 0.02 & 0.01 & 0.06 & 0.05 & 0.02 & & & \\
\hline${ }^{\mathrm{VI}} \mathrm{Al}$ & & & 2.93 & 2.76 & 0.26 & 0.27 & 2.87 & & & \\
\hline${ }^{\mathrm{IV}} \mathrm{Al}$ & 1.84 & 1.77 & 0.76 & 0.82 & & & & & & \\
\hline $\mathrm{Si}$ & 2.14 & 2.21 & 5.24 & 5.18 & 0.01 & 0.01 & 3.18 & & & \\
\hline$\Sigma\left(\mathrm{Si}+{ }^{\mathrm{IV}} \mathrm{Al}\right)$ & 3.98 & 3.98 & 6.00 & 6.00 & - & - & - & - & - & - \\
\hline
\end{tabular}

(*) Total $\mathrm{Fe}$ as $\mathrm{FeO}^{\mathrm{T}}$ except for magnetites $\left(\mathrm{Fe}_{2} \mathrm{O}_{3}{ }^{\mathrm{T}}\right)$. Number of cations calculated following Papike $(1987,1988)$ and the appendices in Deer et al. (2013) based on 8 (anorthite), 18 (indialite), 3 (magnetite), 11 (muscovite) $\mathrm{O}$ atoms per formula unit. Mineral names are abbreviated according to Whitney and Evans (2010). 
Table 2: Main oxide (XRF results) and trace element contents (ICP-OES results) in whole-rock paralavas and country rocks $(*)$

\begin{tabular}{|c|c|c|c|c|c|c|c|c|c|c|c|c|c|}
\hline $\begin{array}{l}\text { Sample } \\
\text { Source }\end{array}$ & $\begin{array}{c}\text { PAC1 } \\
\text { A }\end{array}$ & $\begin{array}{c}\text { PAC1 } \\
\text { H }\end{array}$ & $\begin{array}{r}\text { PAC2 } \\
\text { A } \\
\text { G }\end{array}$ & $\begin{array}{l}\text { PAC2 } \\
\quad \text { J } \\
\\
\text { uy }\end{array}$ & $\begin{array}{l}\text { Profile } \\
\text { La Ricam }\end{array}$ & \begin{tabular}{l|l} 
le 3 & \\
marie, Lo
\end{tabular} & \multicolumn{5}{|c|}{$\begin{array}{c}\text { Garcia } \\
\text { Bulk paralava }\end{array}$} & \multicolumn{2}{|c|}{$\begin{array}{c}\text { Garcia } \\
\text { Stephanian }\end{array}$} \\
\hline \multicolumn{14}{|c|}{ Main oxide contents [wt\%] } \\
\hline $\mathrm{SiO}_{2}$ & 55.2 & 58.0 & 57.2 & 57.5 & 56.9 & 58.1 & 54.69 & 56.52 & 55.78 & 56.12 & 55.17 & 55.13 & 48.97 \\
\hline $\mathrm{TiO}_{2}$ & 0.71 & 0.72 & 0.77 & 0.77 & 0.75 & 0.74 & 0.70 & 0.73 & 0.74 & 0.73 & 0.72 & 0.74 & 0.41 \\
\hline $\mathrm{Al}_{2} \mathrm{O}_{3}$ & 25.94 & 23.37 & 24.78 & 24.54 & 25.38 & 25.02 & 24.33 & 25.30 & 24.97 & 25.03 & 24.56 & 22.78 & 10.67 \\
\hline $\mathrm{Fe}_{2} \mathrm{O}_{3}{ }^{\mathrm{T}}$ & 8.15 & 7.97 & 7.93 & 8.13 & 7.75 & 7.59 & 7.98 & 7.89 & 8.14 & 8.43 & 8.16 & 4.68 & 18.22 \\
\hline $\mathrm{MnO}$ & 0.11 & 0.12 & 0.13 & 0.13 & 0.11 & 0.12 & 0.06 & 0.07 & 0.14 & 0.14 & 0.14 & 0.03 & 0.49 \\
\hline $\mathrm{MgO}$ & 1.63 & 1.52 & 1.62 & 1.62 & 1.57 & 1.48 & 1.06 & 1.10 & 1.58 & 1.62 & 1.59 & 1.75 & 2.35 \\
\hline $\mathrm{CaO}$ & 1.85 & 1.86 & 1.98 & 1.80 & 1.61 & 1.71 & 1.78 & 1.65 & 1.59 & 1.72 & 1.62 & 0.26 & 1.87 \\
\hline $\mathrm{Na}_{2} \mathrm{O}$ & 0.41 & 0.42 & 0.40 & 0.38 & 0.41 & 0.42 & 0.41 & 0.37 & 0.37 & 0.39 & 0.39 & 0.30 & 0.95 \\
\hline $\mathrm{K}_{2} \mathrm{O}$ & 4.74 & 4.94 & 4.91 & 4.96 & 4.88 & 4.85 & 4.87 & 4.71 & 4.90 & 5.05 & 4.83 & 5.04 & 1.94 \\
\hline $\mathrm{P}_{2} \mathrm{O}_{5}$ & 0.22 & 0.23 & 0.21 & 0.21 & 0.19 & 0.20 & 0.27 & 0.28 & 0.27 & 0.29 & 0.27 & 0.10 & 0.71 \\
\hline LOI & 1.08 & 0.85 & 0.86 & 0.75 & 1.15 & 0.55 & 2.69 & 1.19 & 0.92 & 0.67 & 0.95 & 8.63 & 12.97 \\
\hline Total & 100.0 & 100.0 & 100.8 & 100.8 & 100.8 & 100.7 & 98.8 & 99.8 & 99.4 & 100.2 & 98.4 & 99.44 & 99.55 \\
\hline
\end{tabular}

\begin{tabular}{|c|c|c|c|c|c|c|c|c|c|c|c|c|c|}
\hline Sc & 18.9 & 16.7 & 17.12 & 17.46 & 17.52 & 17.09 & 19.5 & 20.1 & 18.4 & 19.1 & 19.9 & 20.7 & 9.2 \\
\hline $\mathrm{V}$ & 129 & 120 & 131.8 & 128.9 & 137.8 & 127.6 & 126 & 135 & 144 & 139 & 135 & 150 & 48 \\
\hline $\mathrm{Cr}$ & 303 & 756 & 110.1 & 99.4 & 102.9 & 97.7 & 97 & 101 & 100 & 100 & 102 & 105 & 36 \\
\hline $\mathrm{Ni}$ & 151 & 363 & 46.0 & 43.1 & 42.0 & 40.8 & 34.6 & 42.1 & 51.3 & 51.5 & 50.5 & 44 & 17 \\
\hline $\mathrm{Cu}$ & 52 & 92 & 75.0 & 105.4 & 71.6 & 121.5 & na & na & na & na & na & 33 & 9 \\
\hline $\mathrm{Zn}$ & 794 & 215 & 1048 & 14.1 & 723 & 21.2 & 229 & 90.2 & 3.54 & 69 & 4.23 & 95 & 73 \\
\hline $\mathrm{Ga}$ & na & na & 41.6 & 18.8 & 43.3 & 30.0 & 38.3 & 38.4 & 20.6 & 43 & 15.5 & 34.3 & 16.3 \\
\hline $\mathrm{Rb}$ & na & na & na & na & na & na & 280 & 287 & 304 & 306 & 298 & 343 & 152 \\
\hline $\mathrm{Sr}$ & 167 & 168 & 196.4 & 170.0 & 171.5 & 163.8 & 200 & 174 & 167 & 169 & 173 & 84 & 87 \\
\hline $\mathrm{Y}$ & 42.3 & 40.5 & 41.3 & 41.3 & 40.6 & 38.5 & 40.8 & 39.8 & 41.6 & 42 & 41.2 & 39.4 & 54.1 \\
\hline $\mathrm{Zr}$ & na & na & na & na & na & na & 129 & 131 & 139 & 140 & 135 & 127 & 105 \\
\hline $\mathrm{Nb}$ & 17.2 & 18.2 & na & na & na & na & 17.8 & 18.9 & 18.7 & 18.1 & 18.5 & 18.5 & 13.8 \\
\hline $\mathrm{Ba}$ & 1158 & 1141 & 900 & 835 & 1197 & 1123 & 779 & 829 & 748 & 922 & 745 & 407 & 254 \\
\hline $\mathrm{La}$ & 65.5 & 62.5 & 59.3 & 62.0 & 57.0 & 53.0 & 73.7 & 68.8 & 71.5 & 68.6 & 69.1 & 53.0 & 29.6 \\
\hline $\mathrm{Ce}$ & 133 & 129 & 120.5 & 127.4 & 115.6 & 109.8 & 136 & 120 & 129 & 129 & 118 & 111 & 76 \\
\hline $\mathrm{Eu}$ & 2.66 & 2.56 & 2.08 & 2.05 & 1.95 & 1.93 & 2 & 2.25 & 1.99 & 1.76 & 2 & 1.37 & 2.65 \\
\hline $\mathrm{Yb}$ & 3.81 & 3.66 & 3.62 & 3.62 & 3.48 & 3.38 & 3.81 & 4.11 & 4.18 & 4.17 & 4.09 & 3.60 & 2.80 \\
\hline
\end{tabular}




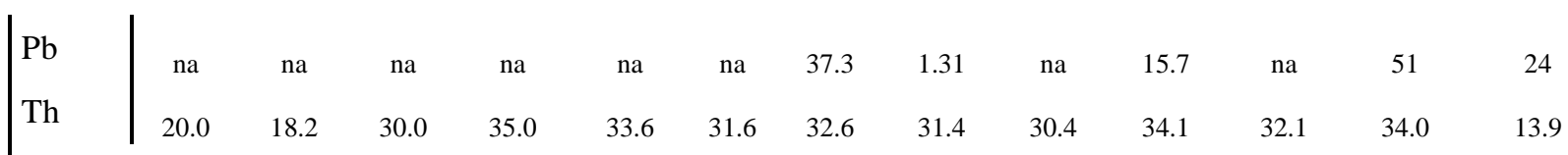

(*) na: not analyzed. Loss on ignition (LOI) determined gravimetrically on separate aliquots. $\mathrm{Fe}_{2} \mathrm{O}_{3}{ }^{\mathrm{T}}=$ total-Fe. All PAC- and DR-samples from La Ricamarie (this study). Column sections taken for chemical profiles (PAC samples) start on A at the edge, ending on $\mathrm{H}$, J, or G from the interior. 


\section{Figure captions}

Fig. $1 \mathbf{a}$-Location of La Ricamarie in the Loire administrative region, France. $\mathbf{b}$ - Outline of the heap on an aerial view in Google Earth (latitude $45.408^{\circ} \mathrm{N}$, longitude $4.358^{\circ} \mathrm{E}$ ). The location of the columnar structures is indicated with a star; the arrow indicates a smoke plume

Fig. 2 Characteristic features of the Saint-Pierre heap in La Ricamarie, France, per November 2014. a - view of a part of the quarry. Color variation due to different mineral content of burnt and unburnt materials; $\mathbf{b}$ - variation of burnt materials in the coal heap; $\mathbf{c}$ - smoking vents on the heap, cf. arrow in Fig. 1 (view towards SE); $\mathbf{d}$ - overview of the columnar zone during heap extraction in 2011, revealing polygonal sections. The size of the cross sections of the prisms is around 0.3-0.5 m, at about $2 \mathrm{~m}$ length; $\mathbf{e}$ - close-up view of the columnar structures. Note the wide gaps between adjacent columns; the tallest columns may be truncated about midway; $\mathbf{f}$ - detailed view of the columns showing the vertical misfit between adjacent columns (center, right center). Columns are colored grey along the outside, gradually turning red inward (also see Fig. 9d)

Fig. $3 \mathbf{a}$ - view of a column: the inward concavity of one face is conspicuous; $\mathbf{b}-$ line sketch of the column in 3a pointing out the inward concave face. Column section : $\sim 0.35 \mathrm{~m} ; \mathbf{c}-$ pustule near the edge of a face between two columns. The pustule is located where the pen is pointing toward the right

Fig 4 Some information on the main samples discussed in the text. Three column pieces have been collected on the field at the foot of the columns presented in Fig. 2e: PAC1, 2, 3. Two of them (PAC2, 3) have been analyzed for AMS (see Figs 9, 10, 11). Slices of the three have been cut into several portions for whole rock geochemical profiles 1, 2, 3 (decimeter scale), 
from A outside to I inside (selected results of analyses in Table 2 and profiles in Fig. 8). A thin section has been prepared in PAC3 and two local profiles (4 and 5, centimeter scale) obtained by EPMA (Fig. 8). Three uncomplete colomn blocks have been taken on the field: DR1, 2, 3. The three have been cut into several portions for whole rock geochemistry (selected results of analyses in Table 2). One thin section has been prepared in DR2A and subject to EPMA (selected results of analyses in Table 1)

Fig. 5 Hypothetical sketch across the columnar zone of the Saint-Pierre burning coal heap (Loire, France) collating observed field features. Columns are overlain by sintered blocks from partial melting. The 'roof' over the columns is compact (predominantly molten) paralava (not studied); the columns under are occasionally seen to be detached. Somewhat smaller upper columns seem separated from lower columns by a horizontal discontinuity. The base of the columns consists of layered paralavas, also known from natural basaltic flows (Boiron 2011; Boiron et al. 2013). Underlying rocks are currently not known

Fig. $6 \mathbf{a}$ - polished slab of paralava; $\mathbf{b}$ - scanned thin-section of the slab revealing the vesicular internal structure; $\mathbf{c}$ - optical micrograph of dendritic spinel blasts in a glassy matrix; $\mathbf{d}$ - ibidem, of elongate mullite crystals; $\mathbf{e}$ - polished slab of clinker showing partial melting (dark porous patches at left); $\mathbf{f}$ - micrograph of a thin-section in plane polarized transmitted light of partially melted clinker containing euhedral light-colored indialite blasts (confirmed by EDS)

Fig. 7 BSE micrographs of partially melted sand-sized detrital minerals; white arrows indicate glass. a - relic quartz surrounded by a small glass corona containing bubbles, at upper right a resorption bay; $\mathbf{b}$ - almost completely resorbed quartz; the original limits of the grain are indicated by a dashed line; $\mathbf{c}$ - partially molten quartz replaced by a new $\mathrm{SiO}_{2}$ polymorph 
(cristobalite-tridymite); the pseudo-hexagonal arrangement of the polymorph is presumably inherited from the quartz; the glass is always slightly brighter than the relic quartz and the $\mathrm{SiO}_{2}$ polymorph; $\mathbf{d}$ - pseudomorph after detrital K-feldspar with syntaxial neogenic feldspar (light grey) in glass matrix (dark grey); outside from the former feldspar grain, the glassy matrix contains bright oxides: tiny grains of hercynite and possibly one small grain of magnetite (square section); $\mathbf{e}$ - pseudomorph after detrital muscovite, expanded aside; $\mathbf{f}$ detail of 7e showing neogenic mullite + glass with tiny hercynites replacing muscovite.

Fig. 8a - EPMA profiles in one thin section from the border of prism PAC3; profile 5 (left side, close to prism border) reveals an outward enrichment in $\mathrm{Zn}$ and some mm-scale gradients for major elements (notably $\mathrm{CaO}, \mathrm{FeO}$ ). $\mathbf{b}$ - Whole-rock geochemical profiles in three separate columns (PAC1, 2, 3) for the major elements (left) and selected trace elements (right); note that major element contents are quite uniform at the decimetre scale; only Zn (and perhaps Ga) displays a visible gradient (outward enrichment) at this scale.

Fig. 9 a - Slab cut from column PAC2, location of panel c indicated with ellipse near center. Paperclip at lower right for scale; $\mathbf{b}$ - location of cut slab within column; $\mathbf{c}$ - detail of elliptical structure near the center of the slab; $\mathbf{d}$-slab cut from column PAC3. Note the grey color along the outside, turning red inward. Numbers refer to ASM samples. Paperclip at lower right for scale, $\mathbf{e}$ - location of cut slab within column

Fig. 10 a - equal-area projections (lower hemisphere) of magnetic susceptibility axes $K_{1}, K_{2}$, and $\mathrm{K}_{3}$ for sample PAC2 $(\mathrm{N}=66)$. The calculated average $\mathrm{K}_{1}$ coincides fairly well with the measured prime axis of the ellipse in Fig. 9c. $\mathbf{b}$ - equal-area projections (lower hemisphere) of magnetic susceptibility axes $\mathrm{K}_{1}, \mathrm{~K}_{2}$, and $\mathrm{K}_{3}$ for sample PAC3 (N=89) 
Fig. 11 a - Classification of $\mathrm{K}_{1}$ values into two groups within column PAC2: one (blue) for the values above the average (the limit equally corresponds to the middle of the amplitude span by the data), and the other (green) for the data below the average. $b$ - Example of continuous variation of $\mathrm{K}_{1}$ values within column PAC3; the total variation runs along a $30^{\circ}$ span, from blue to red

Fig. 12 a Growth of an undulating surface (finger) from a supercooled melt, common in metals and alloys at micrometer scale (e.g. Kurz and Fisher 1992; Stefanescu and Ruxanda 2004), which is valid for solidifying lavas (the scale difference is accounted by the size the thermal gradients, Guy and Le Coze 1990). b in some cases, the planar interface may be stable, with no fingering. $\mathbf{c}$ Formation of a concentric fabric in a growing finger by mineral species or volatile bubbles adhering to the surface. $\mathbf{d}$ The different stages of growth are followed in the order $n, n+1$ from inside to the outside of the finger. The steps proposed in the model of Mattson et al. (2010) contradict this pattern ( $n+1$ inside $n)$ and do not seem likely

Fig. 13 Principle sketch (side view) of a melt zone moving within the heap, following the combustion front. The melt pocket is assumed to extend from several meters to perhaps a several decameters. It is likely to be deep inside the heap, the top of which is not visible on the sketch. The inferred surface and slope may be far from the pocket 

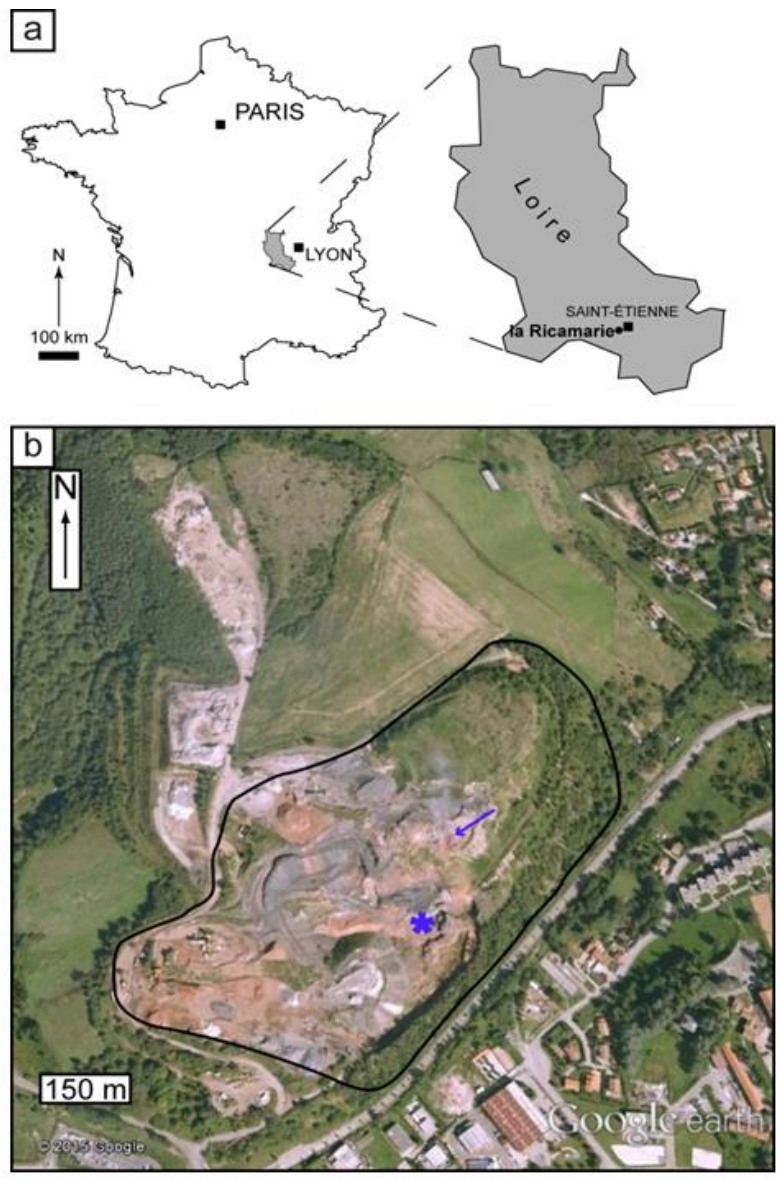

Figure 1 

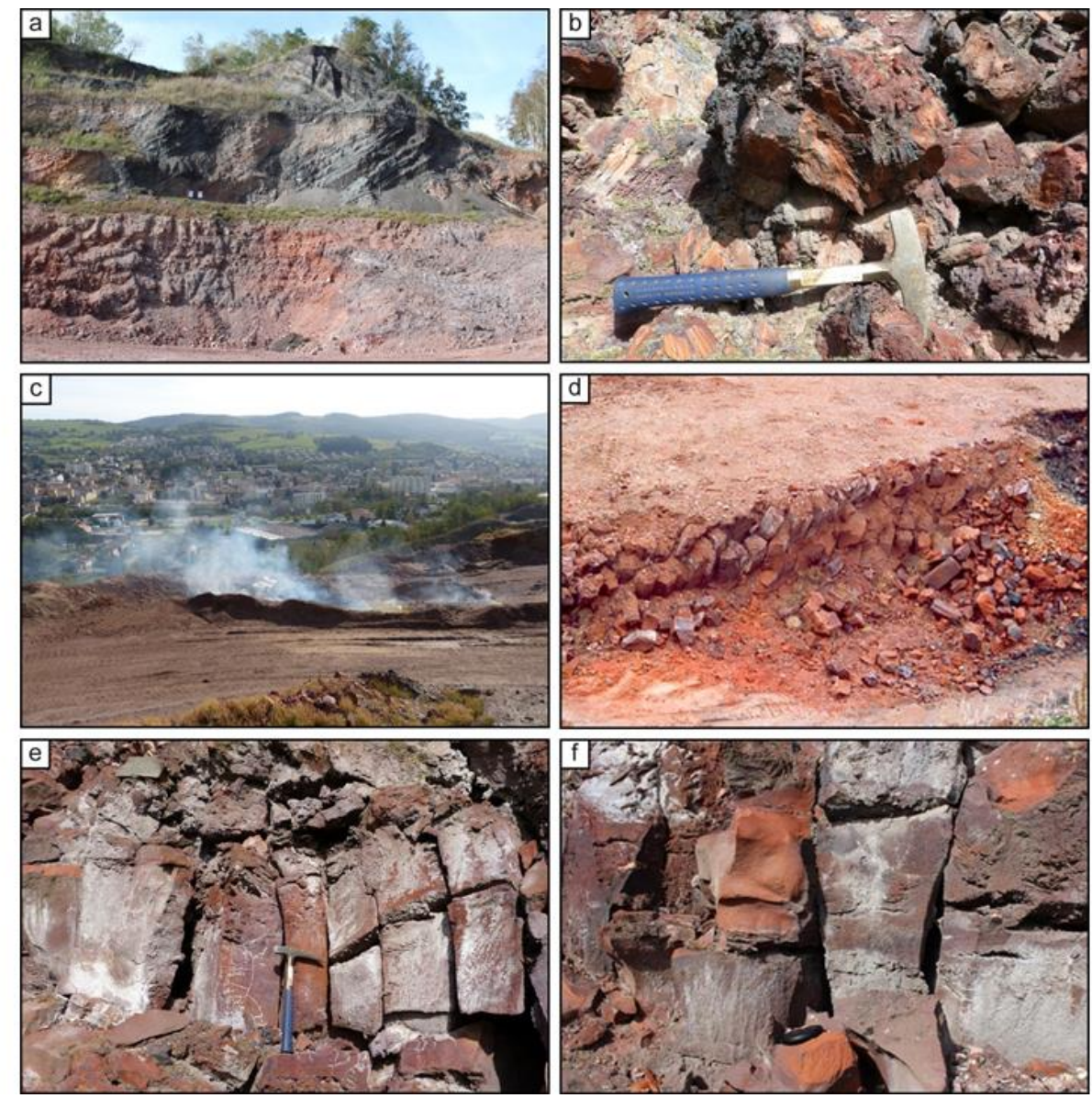

Figure 2 

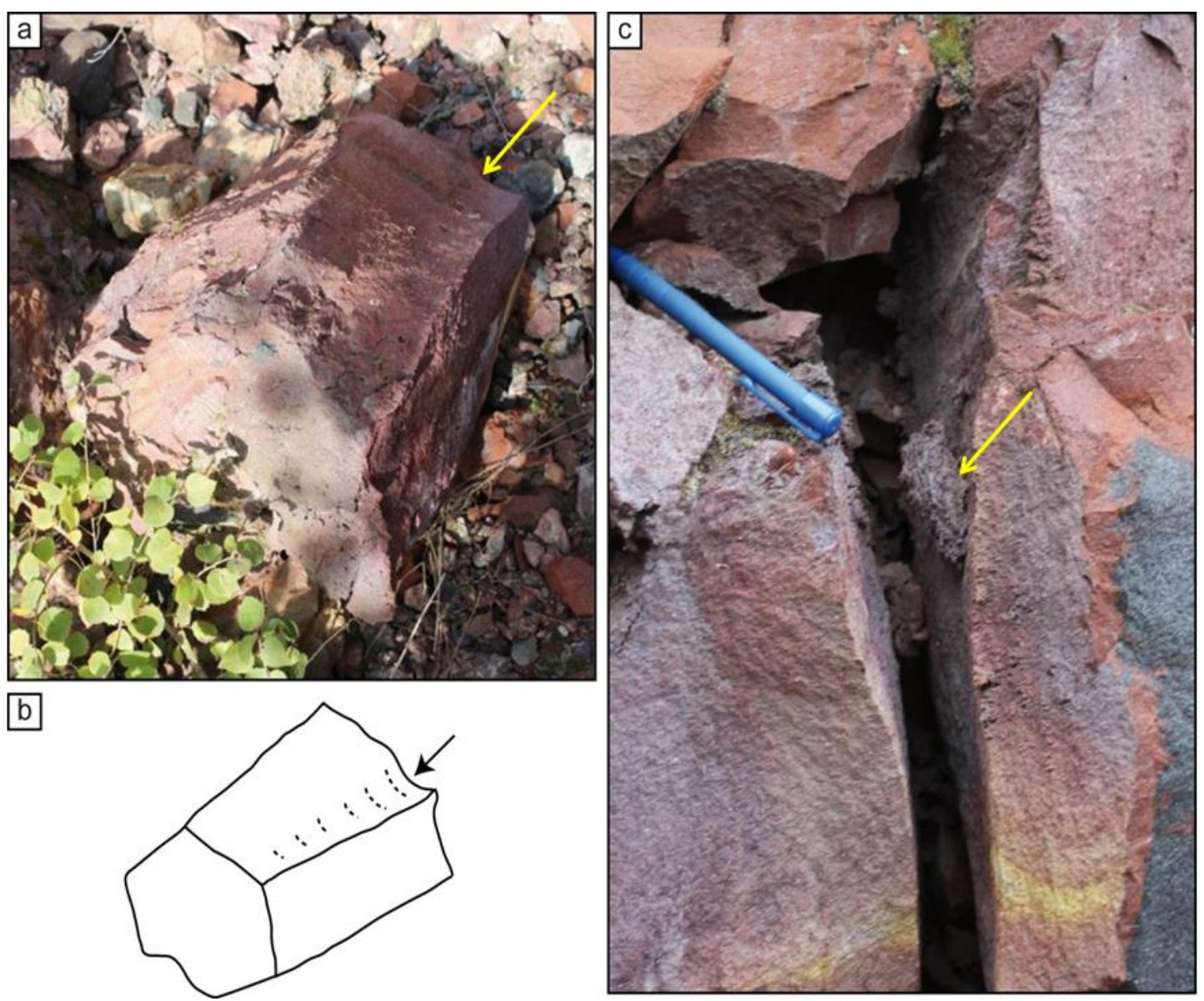

Figure 3 


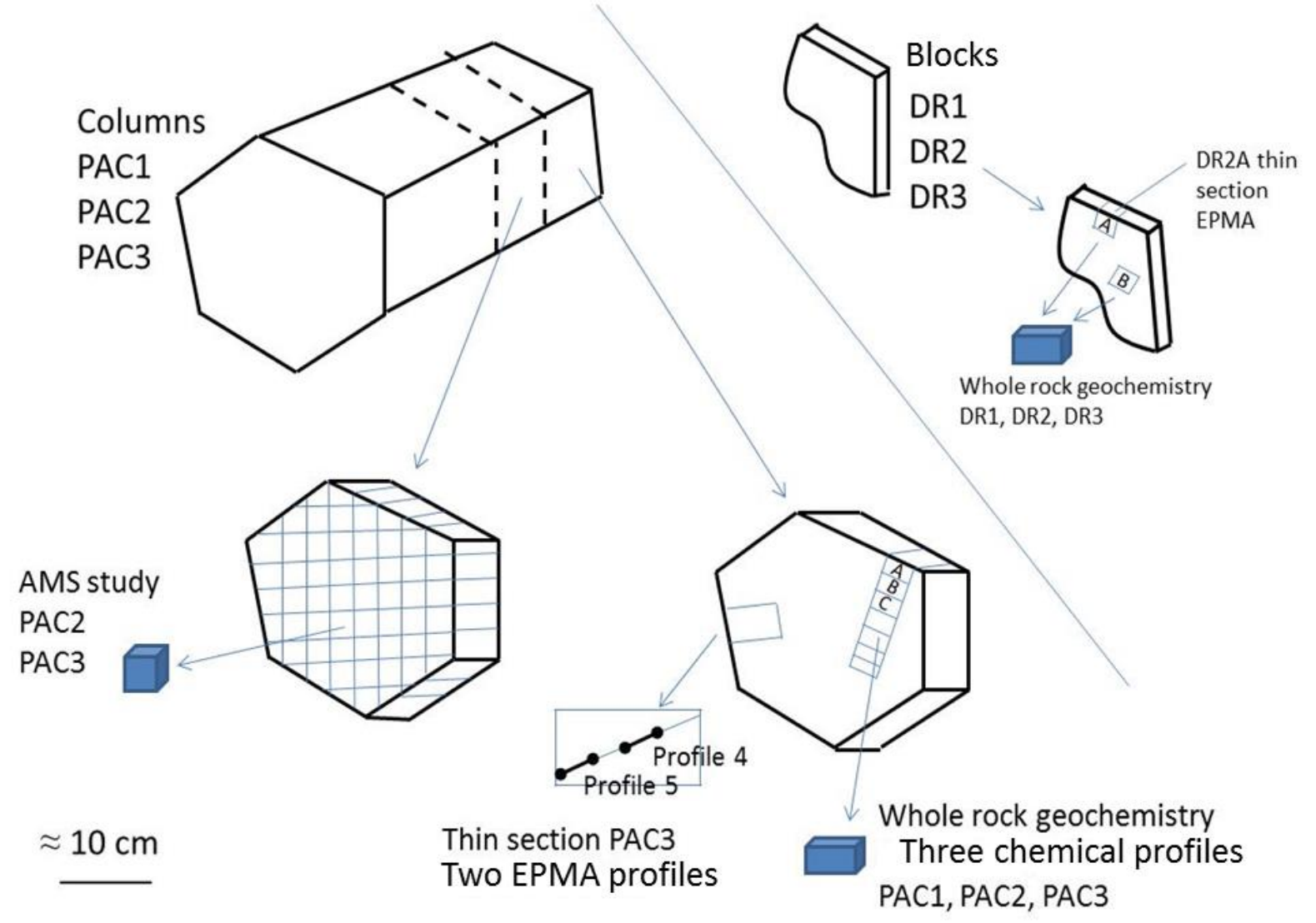

Figure 4 


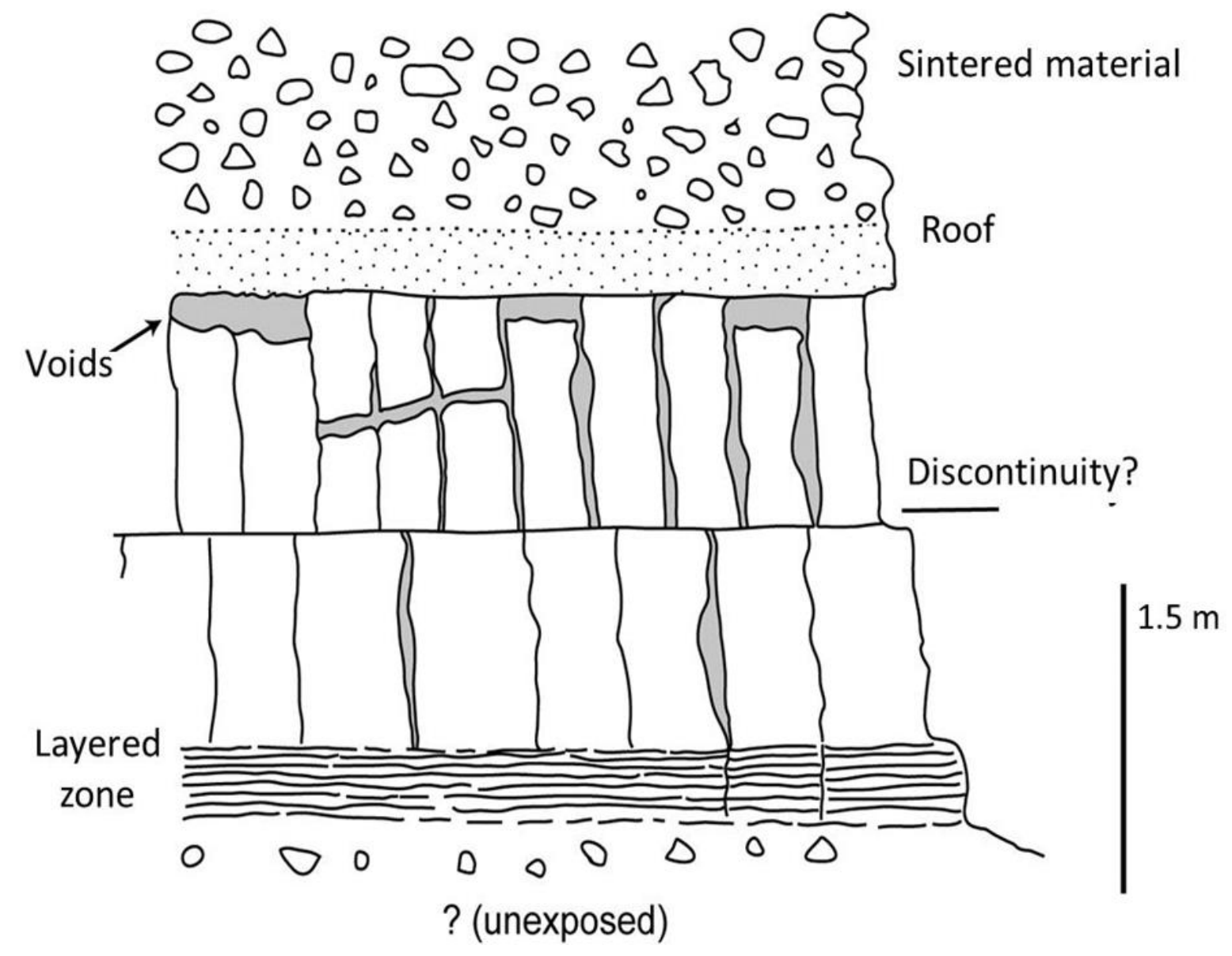

Figure 5 

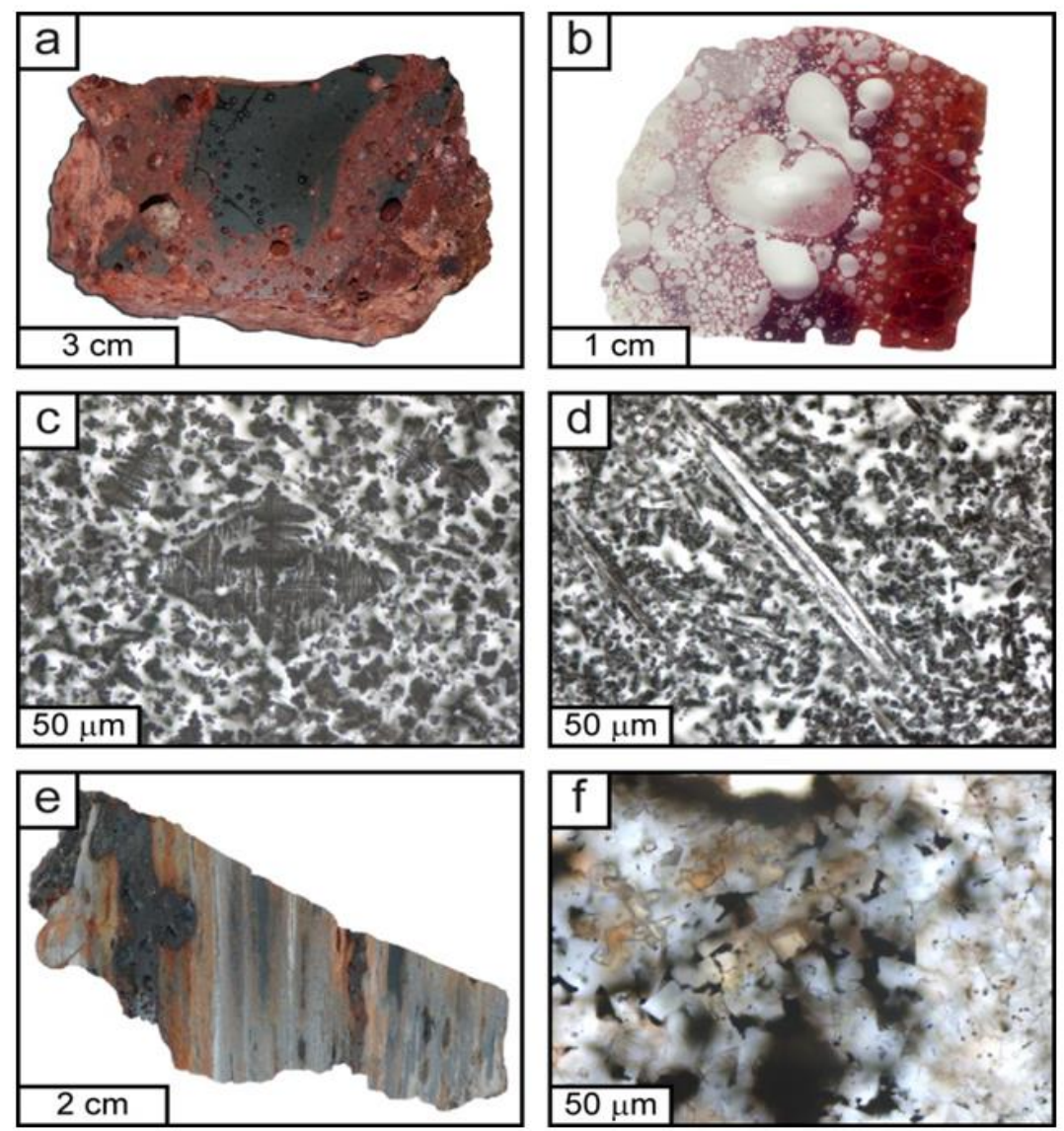

Figure 6 


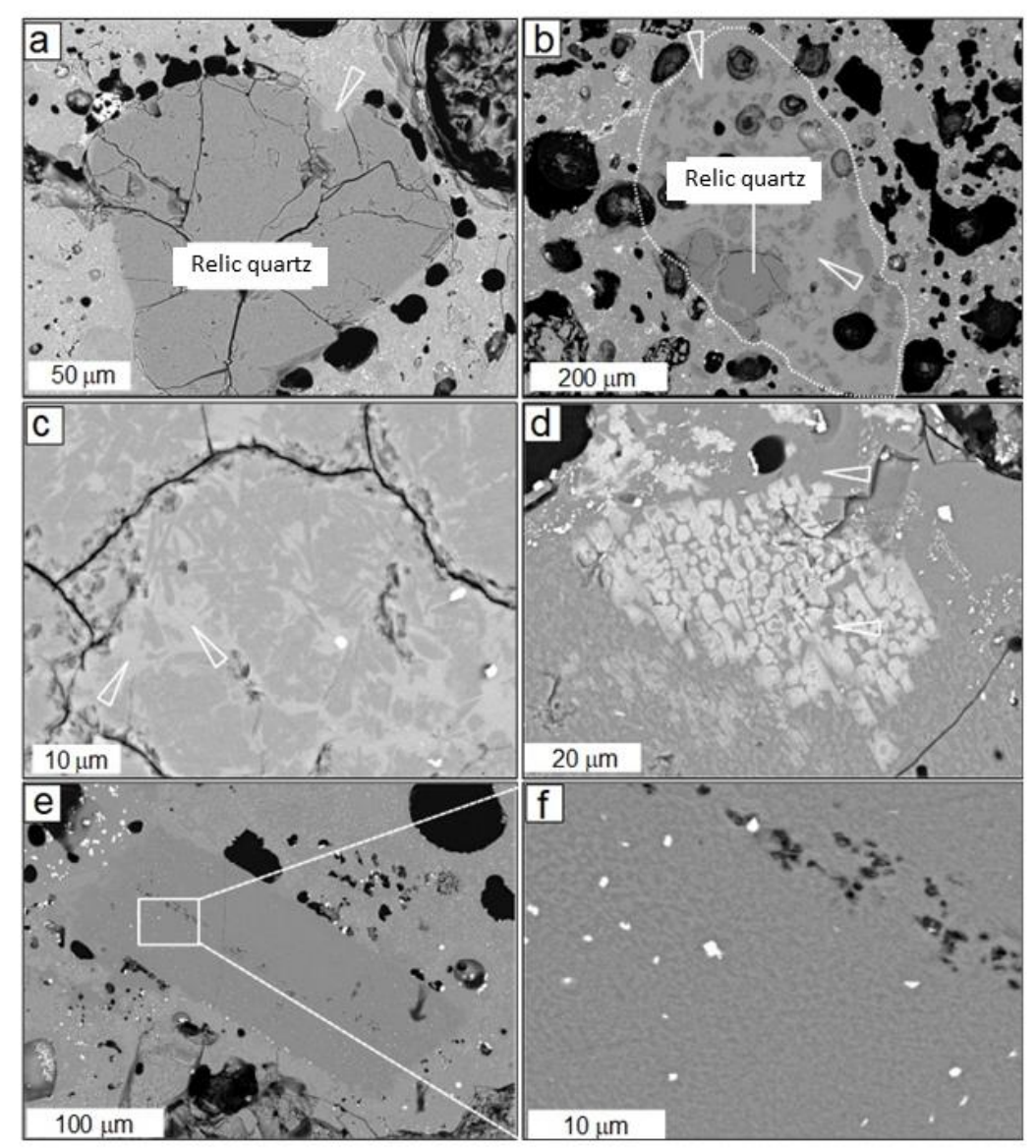

Figure 7 

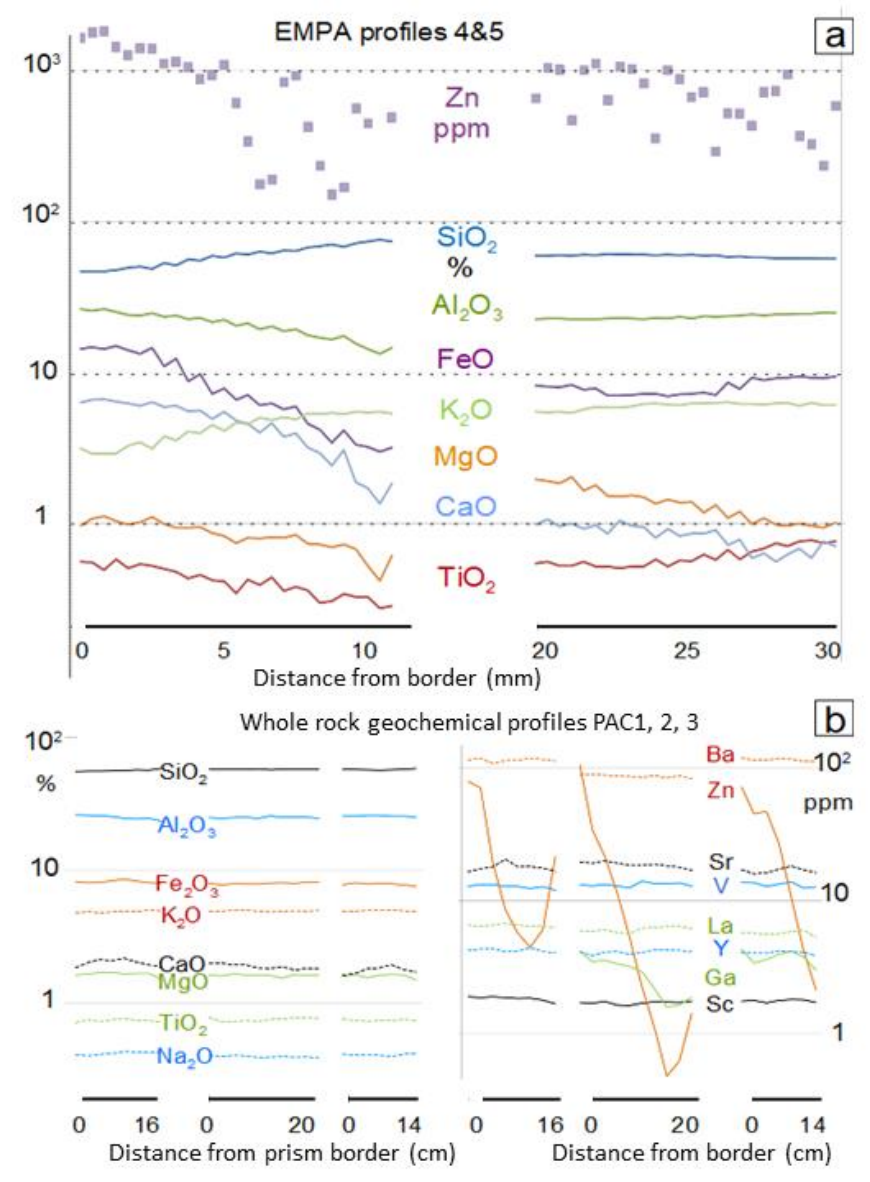

Figure 8 

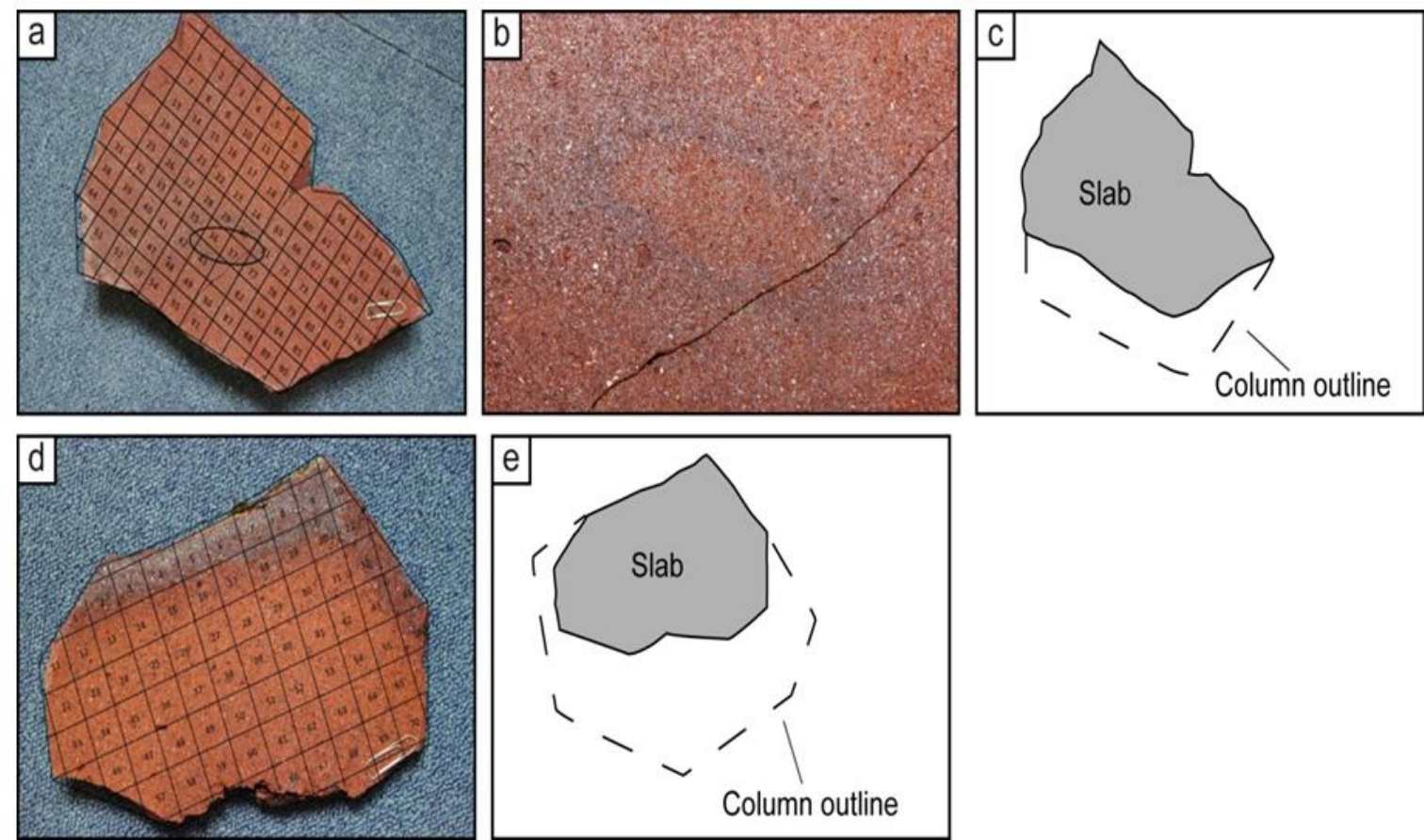

Figure 9 

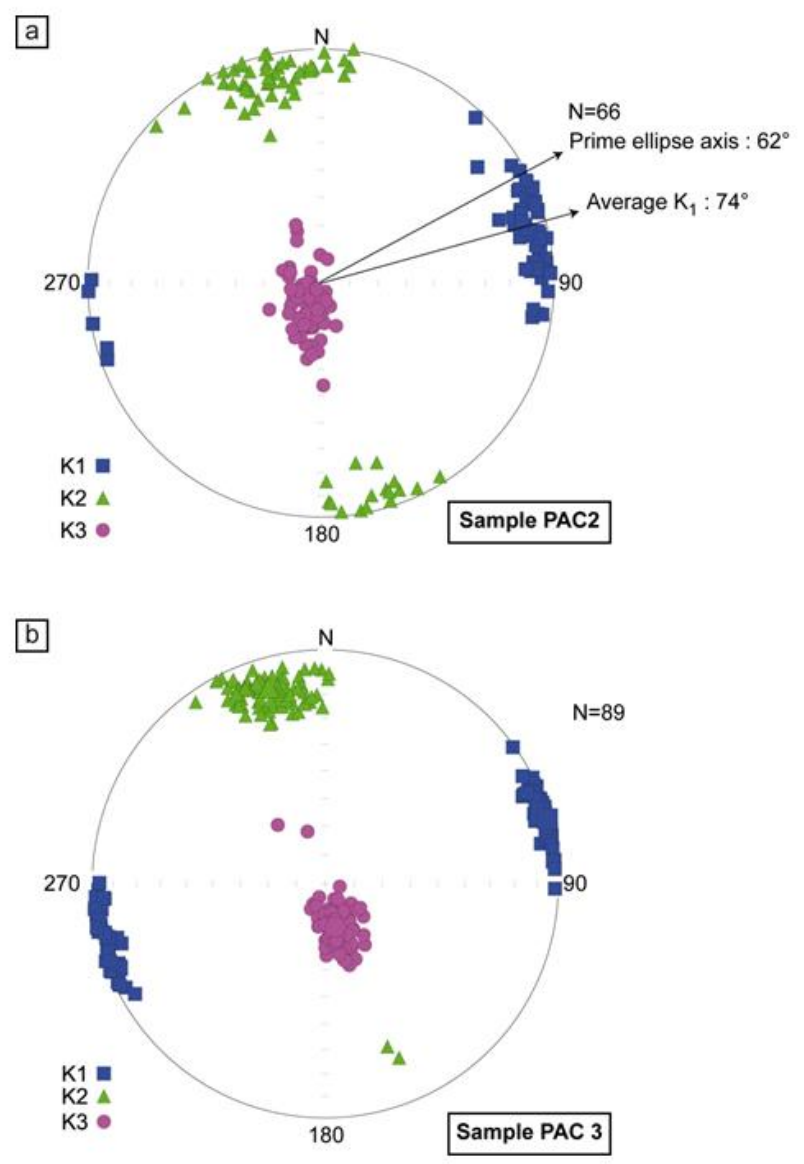

Figure 10 
a

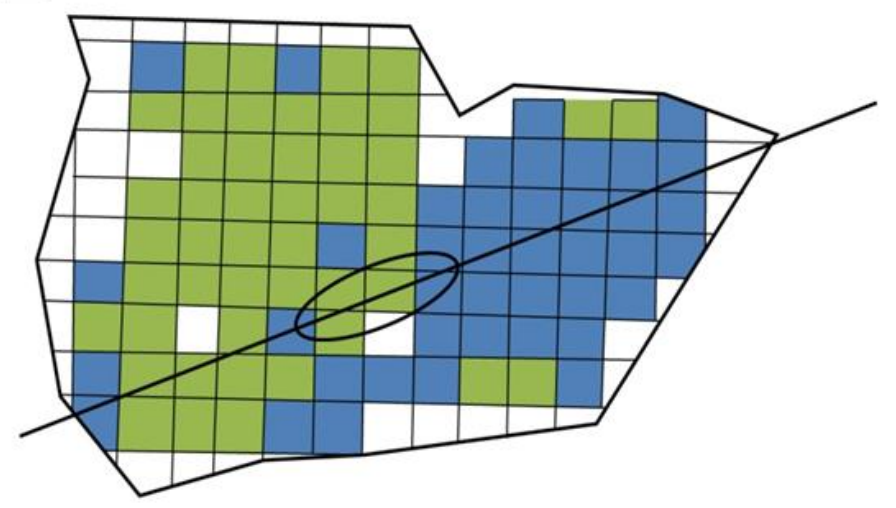

b

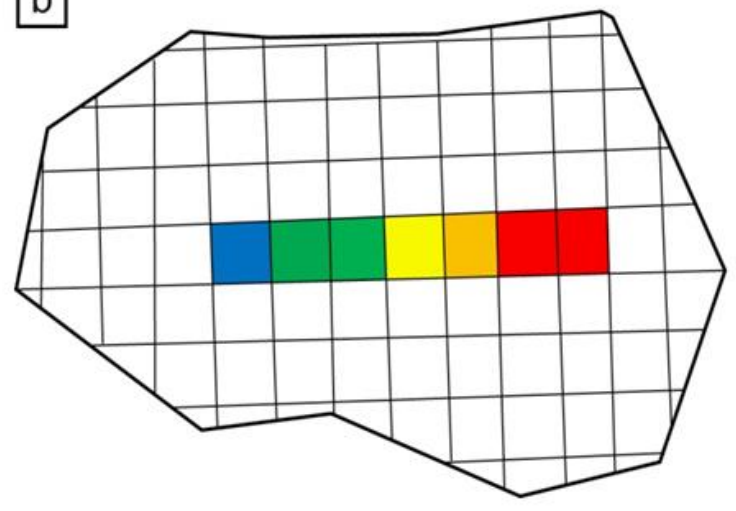

Figure 11 


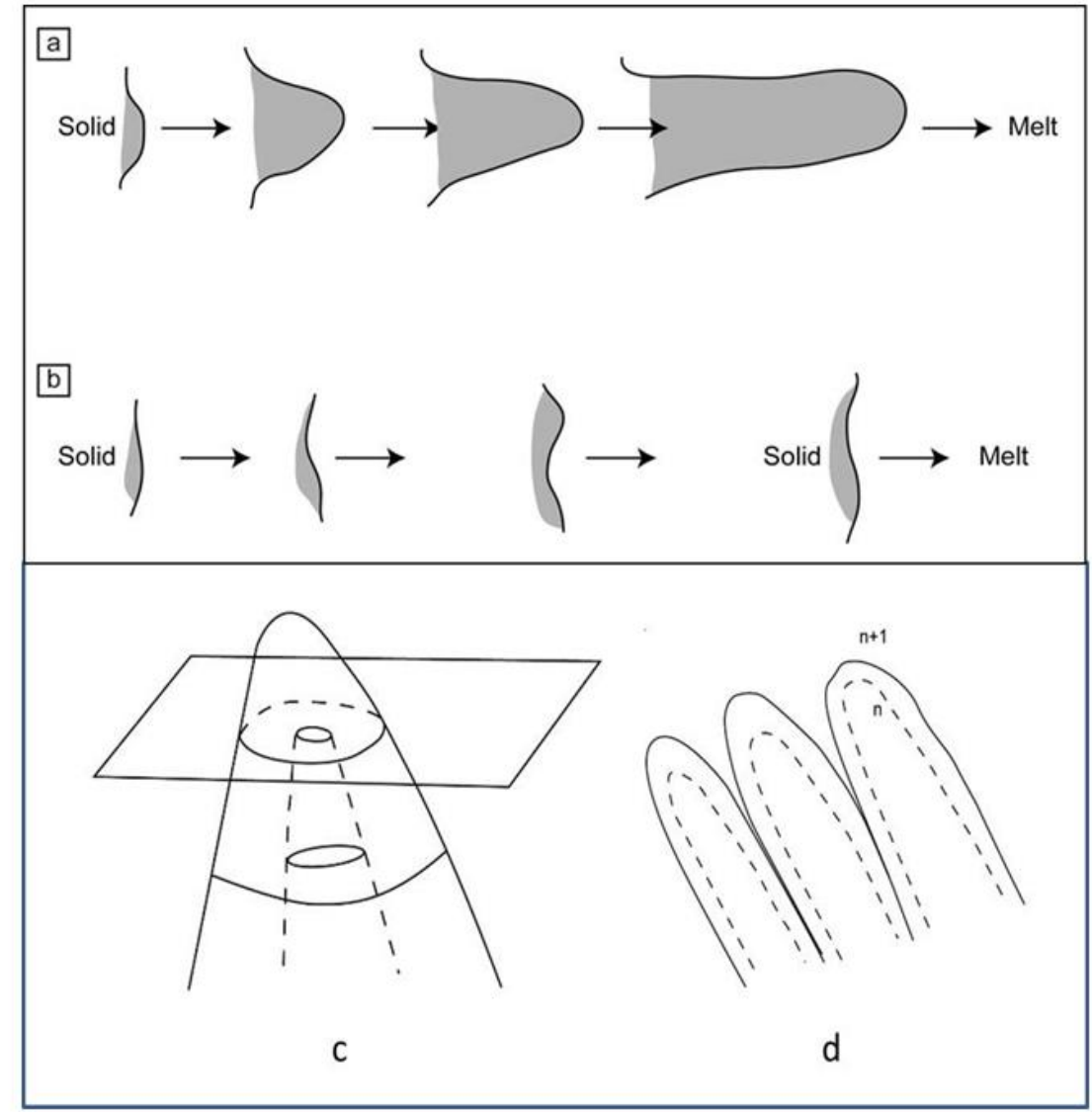

Figure 12 


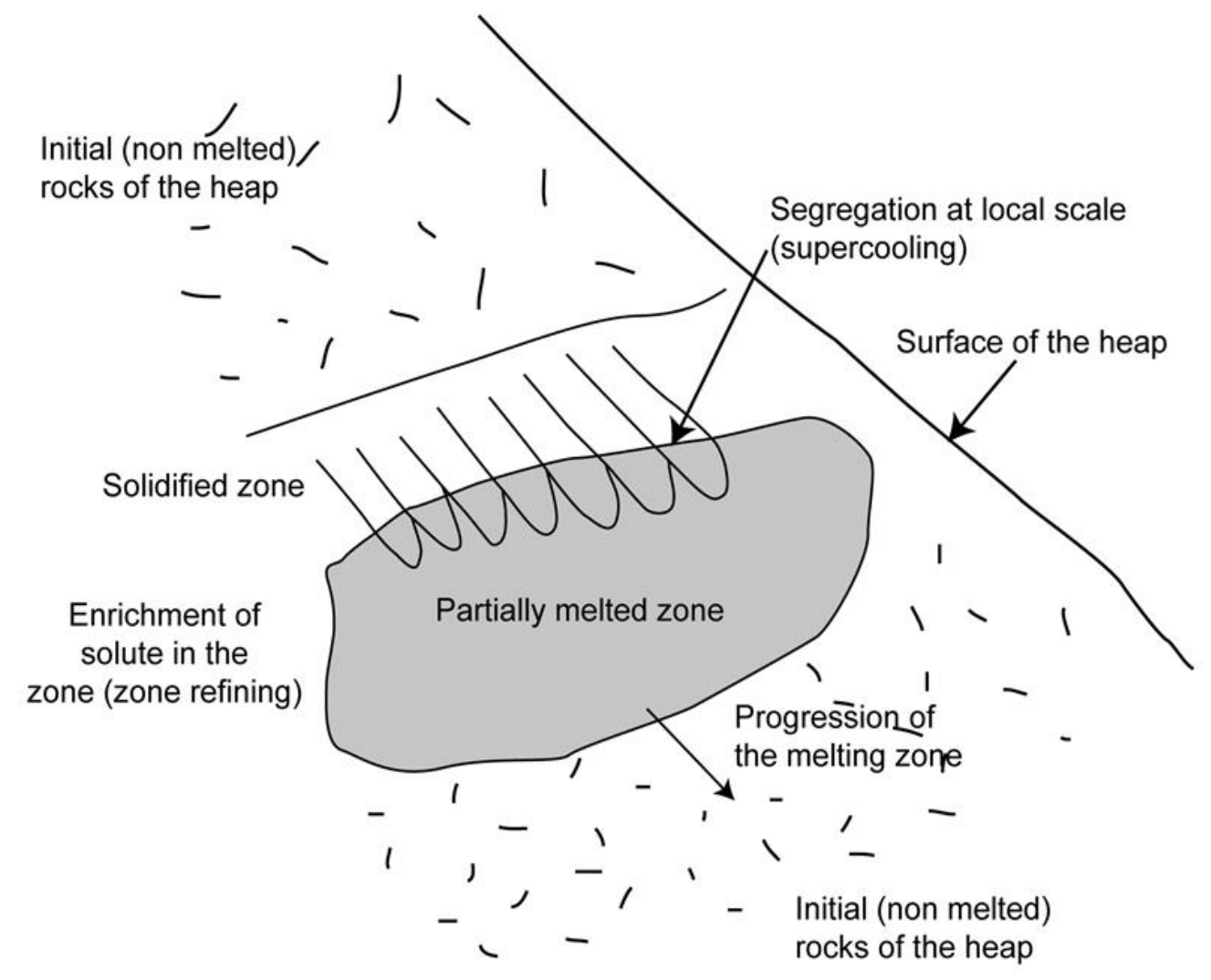

Figure 13 


\section{Columnar structures in pyrometamorphic rocks associated with coal-bearing spoil-heaps burned by self-ignition, La \\ Ricamarie, Loire, France}

Mineralogy and Petrology MIPE-D-19-00066

\section{Supplementary materials}

\section{Thermometry from metal remains in the heap}

An estimate of the temperature in the interior of the heap has been proposed on the basis of the presence of iron exsolutions in magnetite within an old metallic chain found in burnt materials (Guy et al. 2001). The chain was taken from the metal pieces separated by electromagnet before sending the mineral materials into the crushers. The exsolutions of iron are part of a whole set of characters which clearly indicate that they do not come from the industrial manufacture of the chain. The chain in its present state contains a series of brilliant nuclei made of metallic iron. They are surrounded by a gangue of metallic oxide and the various rings of the chain are now welded together by means of the oxide. This is magnetite $\mathrm{Fe}_{3} \mathrm{O}_{4}$ (analysis by X-ray diffraction). The rays of the single oxide $\mathrm{FeO}$ or that of the hydroxylated oxide $\mathrm{FeO}[\mathrm{OH}]$ are not found. The presence of its rays reveals traces of hematite $\mathrm{Fe}_{2} \mathrm{O}_{3}$. Scanning electron microscope (SEM) observation of the different macroscopically observed envelopes was performed.

The different zones that can be distinguished are the following: central zone 1: iron; Zone 2: magnetite with metallic iron patches in the crystal joints of the magnetite and exsolutions of metallic iron within magnetite crystals; Zone 3: magnetite without traces of metallic iron. The phase diagram $\mathrm{Fe}-\mathrm{O} / \mathrm{T}$ ( $\mathrm{Fe}-\mathrm{O}$ phases as a function of the proportion $\mathrm{Fe} / \mathrm{O}$ and depending on T) makes it possible to propose an interpretation of these textures (Guy et al. 2001). This is done as a function of a decrease in temperature, from the maximum reached, and as a function of the oxygen content of the material, imposed by an oxygen pressure gradient from the center to the periphery. Zone 2 gives the most important keys for understanding the history of the chain. Thus the precipitation of iron in the grain boundaries of magnetite is interpreted as the crystallization of a liquid with a composition close to $\mathrm{FeO}$, which solidifies into a mixture of iron and wüstite $\mathrm{FeO}$. It is located in a valley observed in the upper part of the diagram, and the liquid has exceeded the temperature of $1371{ }^{\circ} \mathrm{C}$. The decrease in temperature of the solid $\mathrm{FeO}$ then caused its demixing to iron plus magnetite at a temperature of $560^{\circ} \mathrm{C}$ (lower part of the diagram), a phenomenon responsible of the textures observed inside the magnetite crystals. 
Zone 3 was formed directly of magnetite. It corresponds to the peripheral zone of the chain, the most oxidized. The textures indicate that the magnetite remained solid and that the temperature did not exceed $1583^{\circ} \mathrm{C}$, at which temperature the iron itself would also have melted $\left(\mathrm{T}_{\mathrm{f}}(\mathrm{Fe})=\right.$ $\left.1535^{\circ} \mathrm{C}\right)$. The absence of a hematite zone at the periphery indicates that the oxidation conditions have not reached a sufficiently high level, which is logical in a coal combustion atmosphere. The increase in volume caused by the formation of the oxides is responsible for the apparent swelling of the chain and the "welding" of its constituent elements, as well as the formation of vacuoles arranged in rings in the zonation. As for temperature, these results are in agreement with those of the literature in situations of this type where frequent temperatures of 1200 to $1300^{\circ} \mathrm{C}$ and up to $1650^{\circ} \mathrm{C}$ are reported.

\section{Supplementary figures}
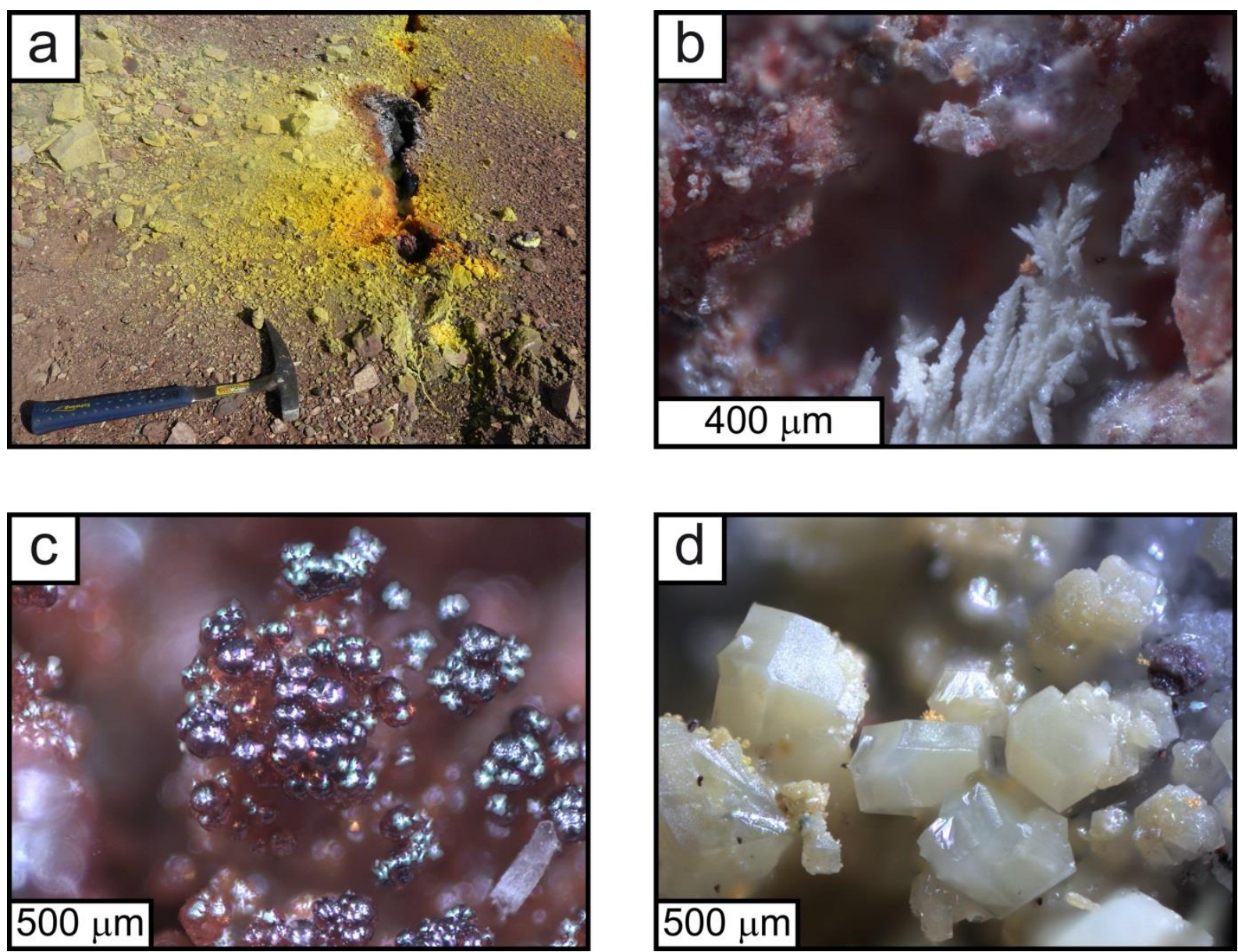

Fig. S1: mineral efflorescences from burning heap fumaroles; $\mathbf{a}$-typical fumarole with efflorescence deposits. b - dendrites of salammoniac $\left(\mathrm{NH}_{4} \mathrm{Cl}\right)$; c - lustrous globules, probably As-S mixture (see eg. Žáček and Skala 2015); d - crystals of sulfur, possibly rosickýite (S) 

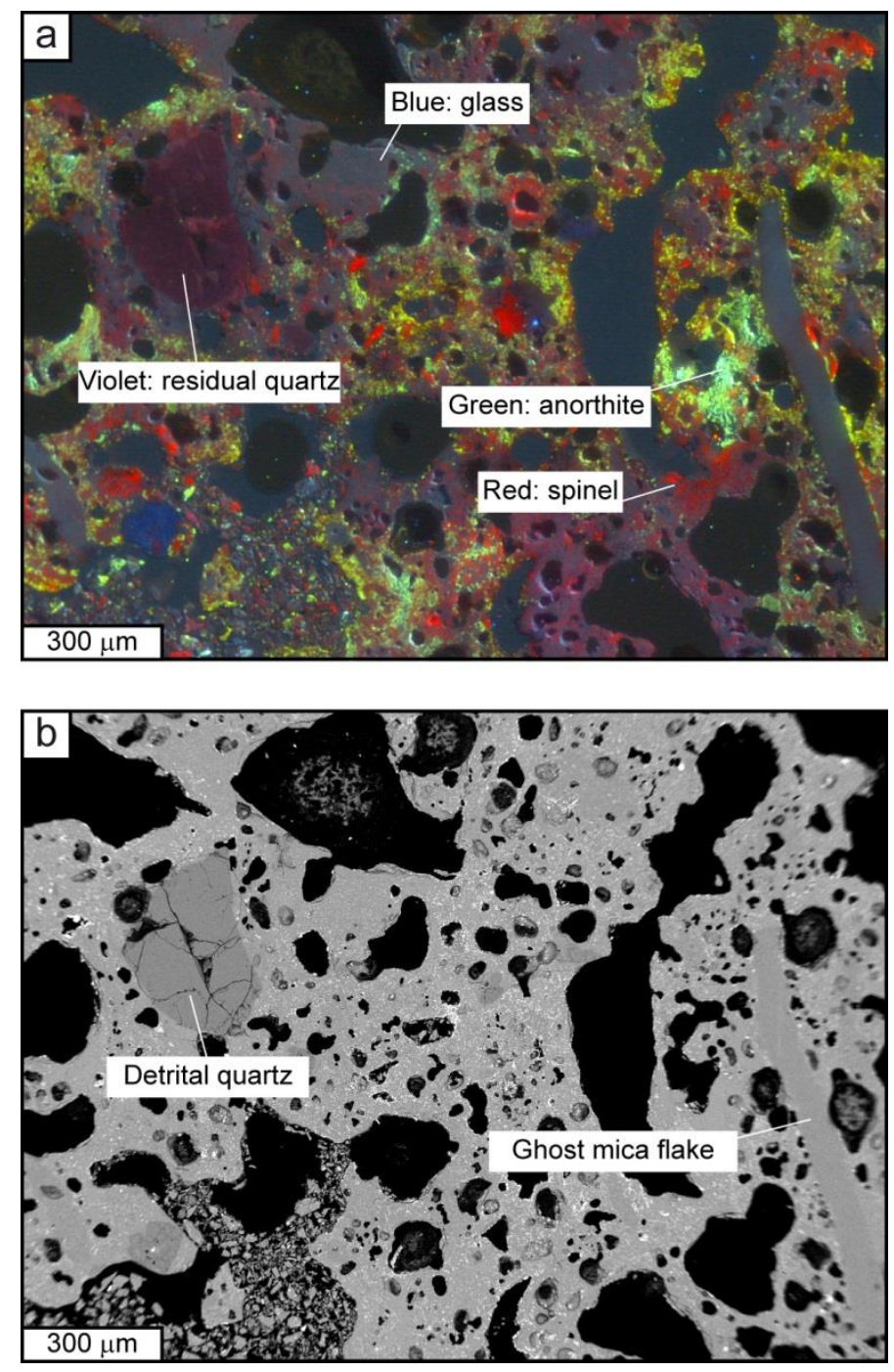

Fig. S2 SEM micrographs of paralava D3C, revealing vesicular structure and sand-sized detrital particles; a cathodoluminescence (SEM-CL). Relic quartz luminesces purple, the glass matrix in dark blue, anorthite in bright green, and spinel appears red. The mullite+glass mica-pseudomorph along the right edge remains dull grey; $\mathbf{b}-$ same area imaged in SEM-BSE 

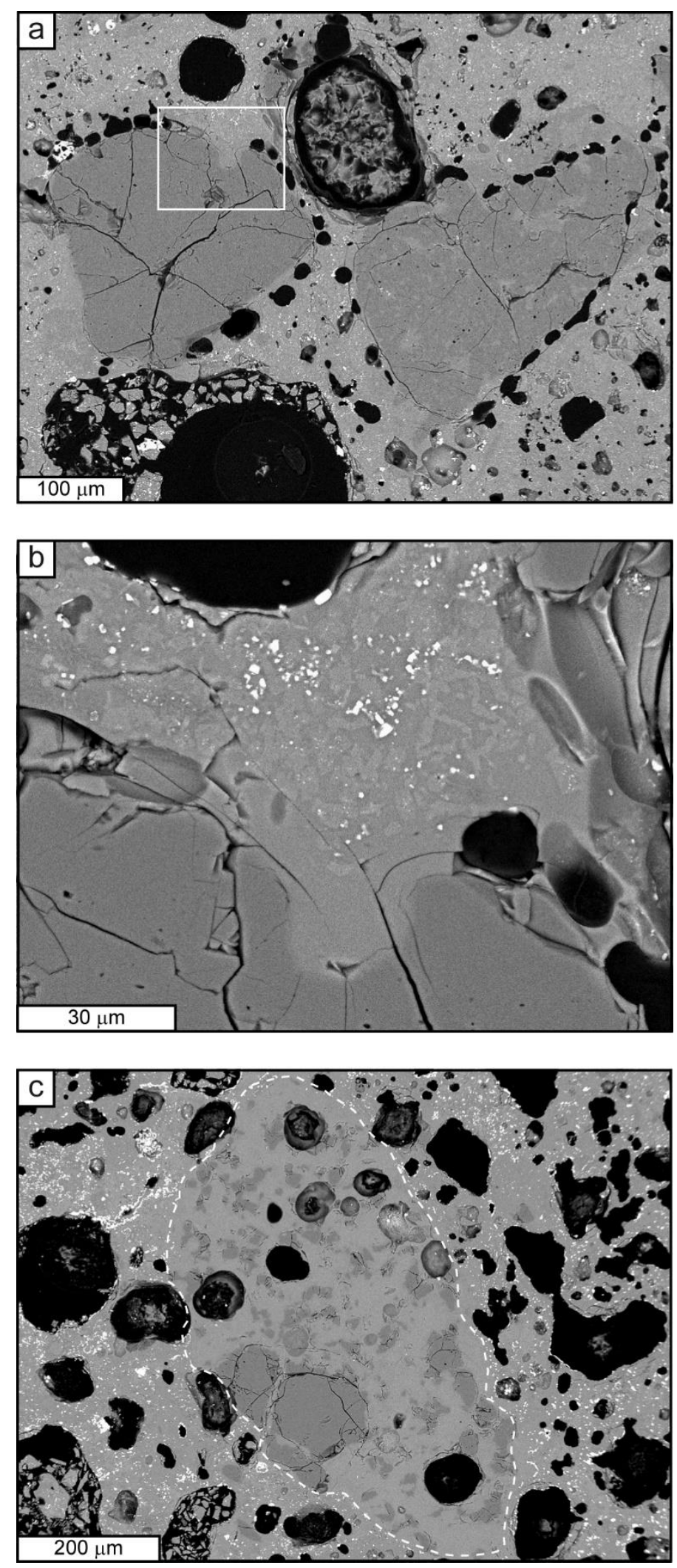

Fig. S3 SEM-BSE micrographs of paralava; $\mathbf{a}$ - resorption of detrital quartz particles by molten glass matrix; $\mathbf{b}-$ detail of panel a showing a glass melt embayment along the particle edge. Bright grains are spinel and/or hematite; c - outline of original quartz particle, now almost completely resorbed by the melt 

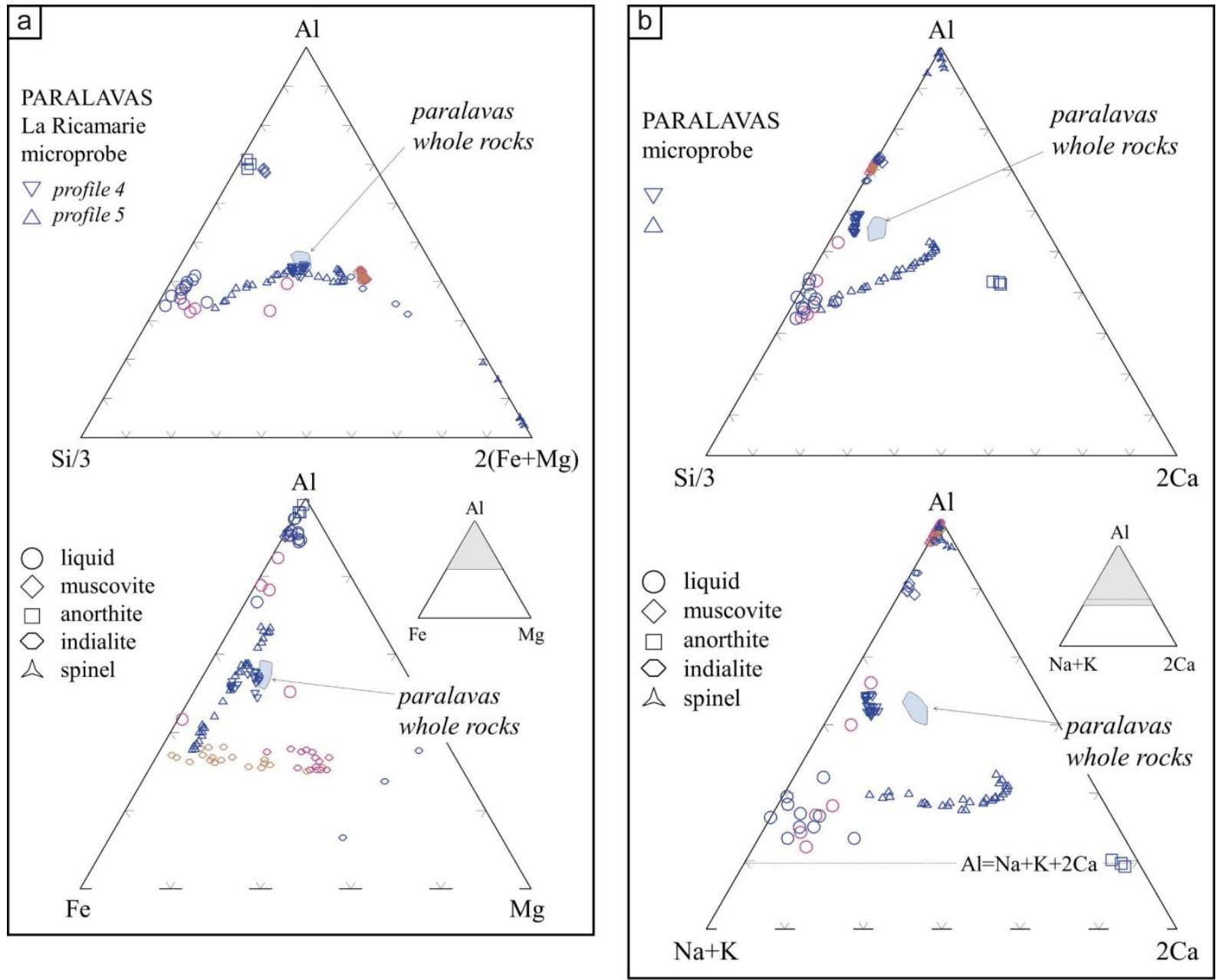

Fig. S4 a - correlation between whole-rock analyses (XRF) and point analyses (EPMA) in the triangles ( $\mathrm{Si} / 3,2(\mathrm{Fe}$ $+\mathrm{Mg}), \mathrm{Al})$ and $(\mathrm{Fe}, \mathrm{Mg}, \mathrm{Al}) ; \mathbf{b}$-ibidem, for triangles $(\mathrm{Si} / 3,2 \mathrm{Ca}, \mathrm{Al})$ and $(\mathrm{Na}+\mathrm{K}, 2 \mathrm{Ca}, \mathrm{Al})$ 

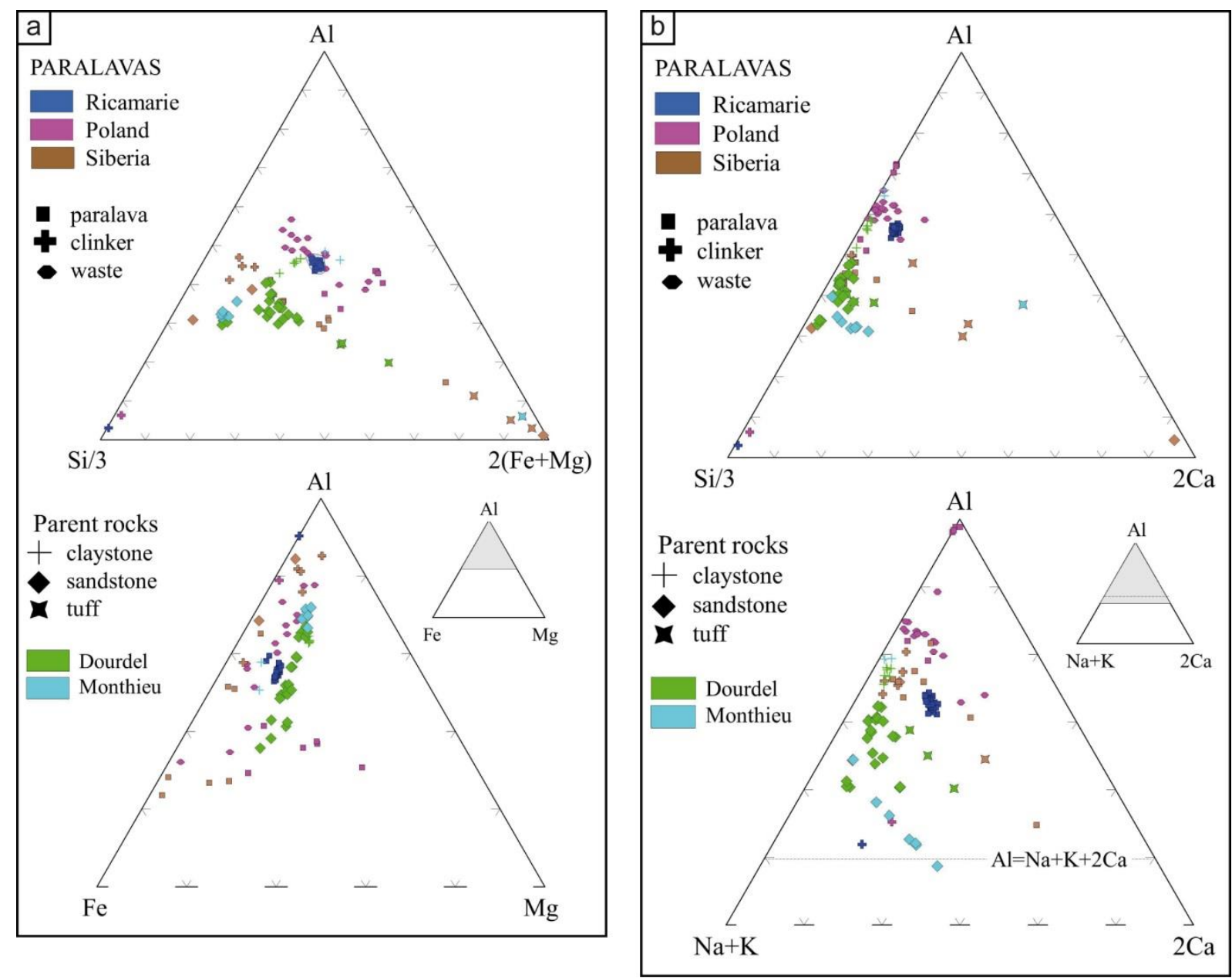

Fig. S5 a - comparison of whole-rock compositions of the paralavas studied here with the coal host rock (Stephanian for Loire deposits Dourdel, Monthieu and Ricamarie) and others from Poland and Siberia (Gaweda et al. 2013) in the triangles $(\mathrm{Si} / 3,2(\mathrm{Fe}+\mathrm{Mg}), \mathrm{Al})$ and $(\mathrm{Fe}, \mathrm{Mg}, \mathrm{Al}) ; \mathbf{b}-$ ibidem, for triangles $(\mathrm{Si} / 3,2 \mathrm{Ca}, \mathrm{Al})$ and $(\mathrm{Na}$ $+\mathrm{K}, 2 \mathrm{Ca}, \mathrm{Al})$ 

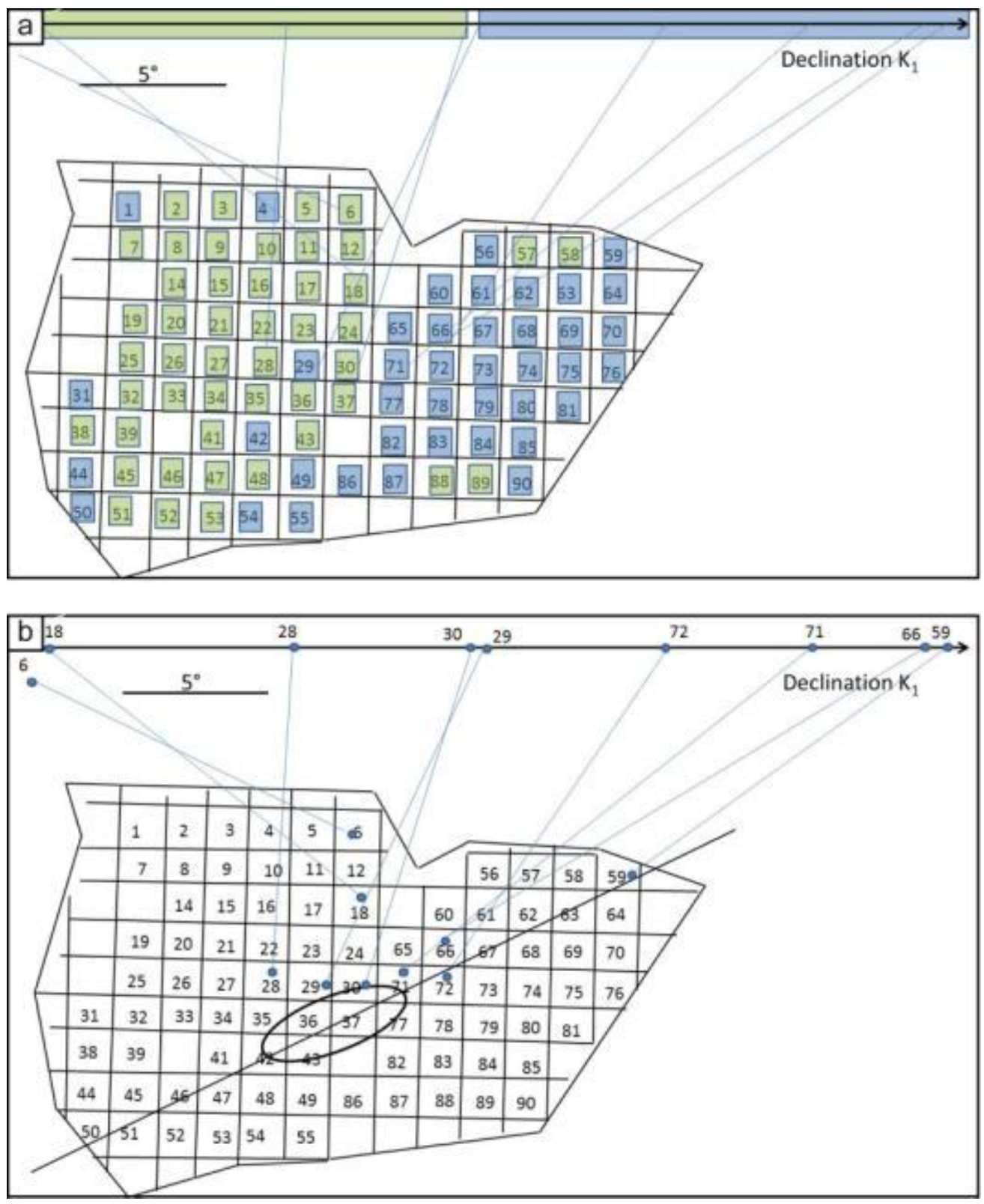

Fig. S6a The values of the directions for $\mathrm{K}_{1}$ have been separated into two groups, greater (in blue) and smaller (green) than the average (PAC2 sample). The sharing in space of the two compositional groups is not governed by chance. Some specific points are discussed in Fig. S6b: correlation of the values of $\mathrm{K}_{1}$ directions with the positions inside the column (PAC2). The difference may exceed some $30^{\circ}$ for points along the direction of the first axis of the ellipse with respect to points located on radiuses perpendicular to it. The two groups defined (Fig. S6a) correspond to relatively separated areas in space; the first, gathering most of the values, lies in the direction close to that of the flow; the second corresponds to most of the values in the perpendicular direction. Points 6 and 18 , located on the same radius with respect to the ellipse (or to the center of the column section) and in a direction perpendicular to the axis of the ellipse have the same declination values, located at end points as compared to the values of points 66 and 59, that are located on another same radius but this time in the direction of the first axis of the ellipse. One can also note the progressive changes of declination for groups of points spatially correlated, as the following points: $28,29,30,71,72(66,59)$ 


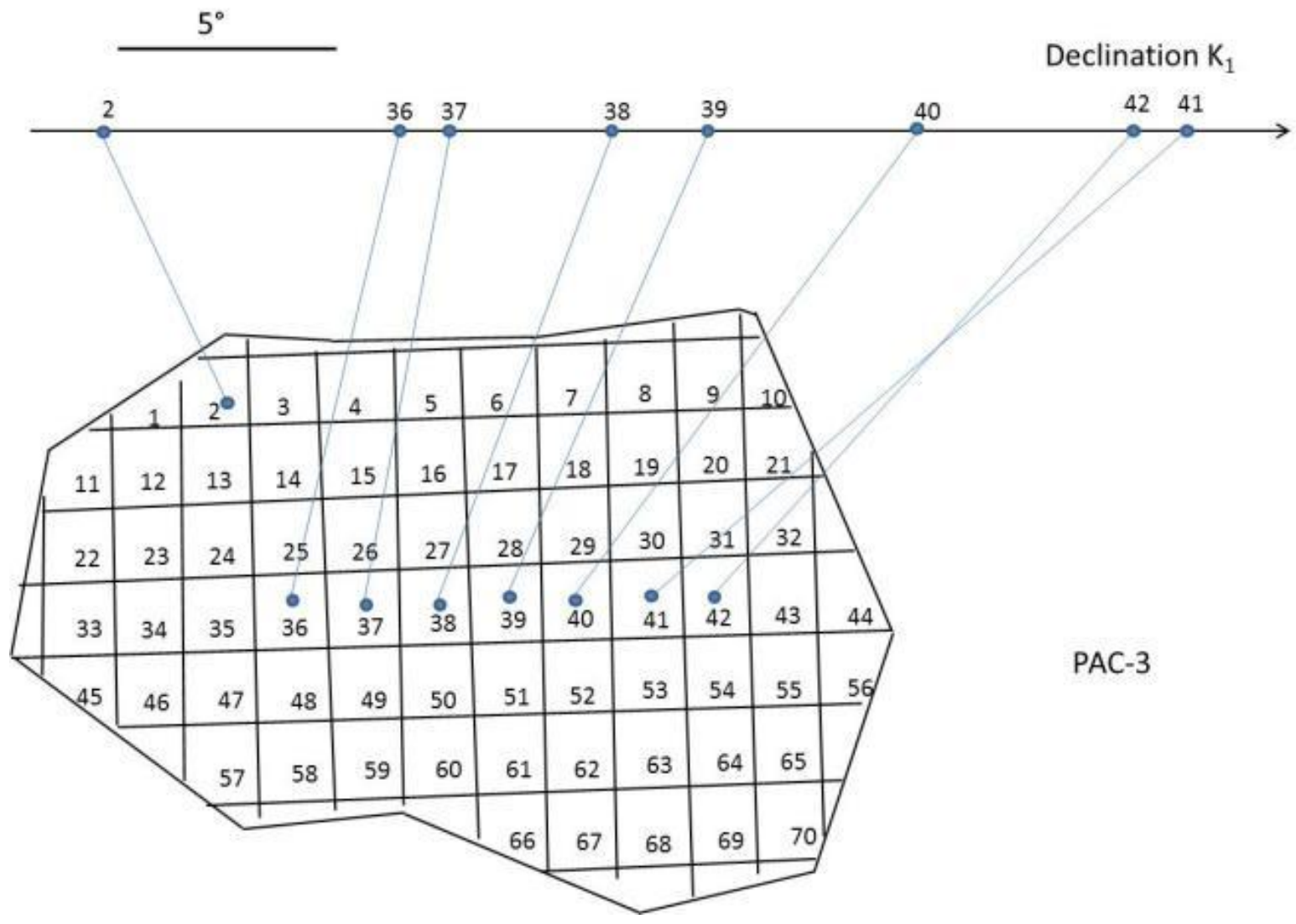

Fig. S7 Correlation of the values of $\mathrm{K}_{1}$ directions with the positions inside the column (PAC3). The sequence of points 36 to $42(36,37,38,39,40,41,42)$ shows a regular increase of declination $K_{1}$ values, in correspondence with a regular movement along a circular ring inside the column and roughly around the center of symmetry of the section. There is a $30^{\circ}$ total variation 

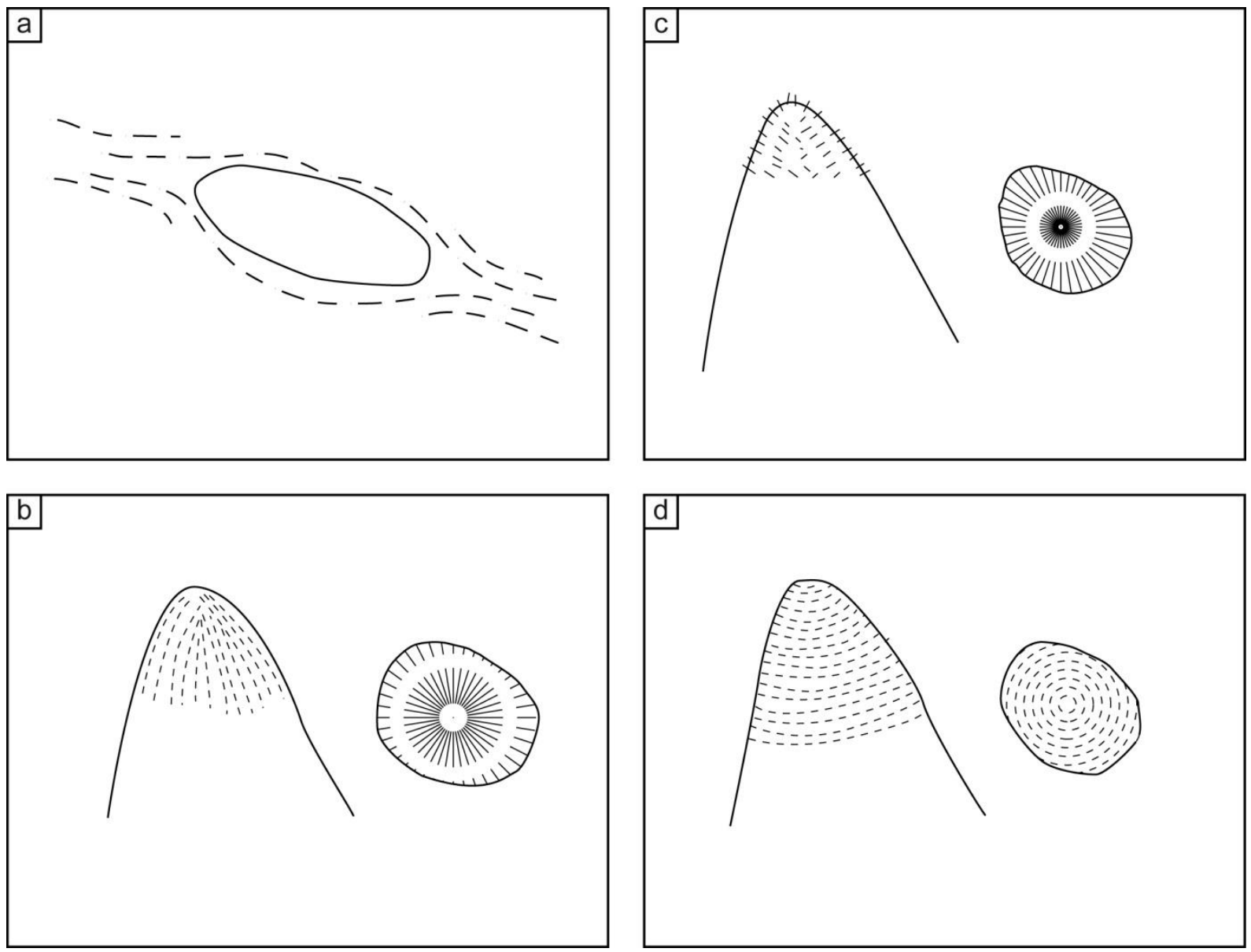

Fig. S8 principle sketch of different options producing oriented mineral textures in 'fingers' during solidification; $\mathbf{a}$ - flow texture marked by elongate or flaky minerals (eg. mica (-pseudomorphs), pyroxene) in the surrounding melt. By contrast, mineral grain growth decorating the finger surface: $\mathbf{b}$ - radial; $\mathbf{c}-$ tangential; $\mathbf{d}$ - concentric 


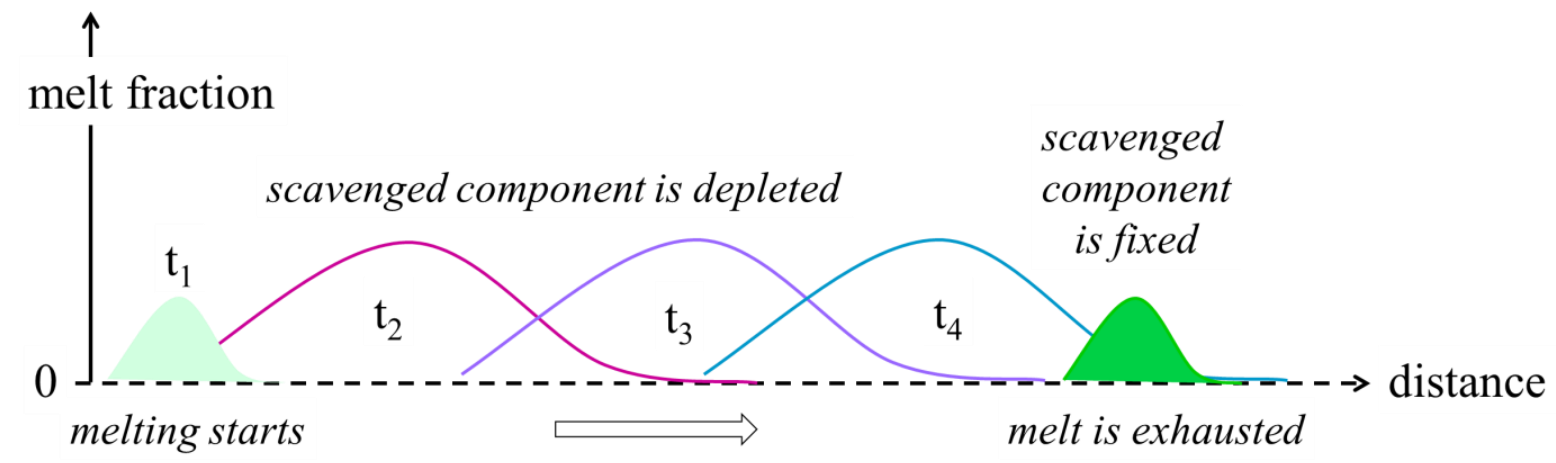

Fig. S9 principle sketch of melt evolution in the burning heap. Over time, the migrating melt (pale green) becomes enriched in element species that are incompatible with the material solidifying at the back, and at the same time depleted from species that are scavenged. The final solid (dark green) that solidifies when the heat source extinguishes will be enriched in incompatible species, this is the case here for $\mathrm{Zn}$ 